\title{
Dam break analysis for BRDA 5 at Worsley Alumina Refinery
}

\author{
GI McPhail Water, Waste and Land, Australia \\ P DiDonna South32, Australia
}

R Ugaz Water, Waste and Land, Australia

\begin{abstract}
South32 Worsley Alumina Pty Ltd operates several bauxite residue storage facilities at their refinery in Western Australia. The bauxite residue slurry is thickened and pumped onto the storage facilities which are constructed on an upstream basis using compacted earthfill embankments. BRDA 5 is the newest of the residue storage facilities, established in 1999, and has a current maximum height of embankment slope of $42 \mathrm{~m}$, of which a compacted earthfill starter embankment makes up the first $22 \mathrm{~m}$. Since 2010, the residue has been treated after deposition using amphirols, which assist in dewatering and compacting the residue. As part of their residue management commitments, Worsley undertook a dam break analysis entailing a review of all available geotechnical testing data, a fault-event analysis to evaluate the probability of removal of support to the residue through slope instability, overtopping, geotechnical piping or failure of a buried structure leading to liquefaction of the residue and a dam break. To model the flow of the liquefied residue, pilot-scale dam break testing was carried out from which estimates of the rheology of the residue were made. The rheology has been incorporated into a flow slide model that applies stream power entropy theory to define the energy changes due to viscous effects and frictional resistance. Benchmarking of the results against modelling using computational fluid dynamics has been made. This paper presents an overview of the dam break assessment process and results that covers a liquefaction potential assessment, a semi-quantified risk assessment based on a fault-event analysis approach, rheological testing of liquefied consolidated residue in a specially developed box rheometer and probabilistic modelling of the dam break, the outflow hydrograph, and the flow inundation areas. It is concluded that incorporation of rheology representative of liquefied consolidated residue in dam break modelling results in significantly reduced prediction of inundation area.
\end{abstract}

Keywords: dam break, flow slide, liquefaction, fault-event tree, rheology, stream power entropy

\section{Introduction}

Following on from recent major tailings storage facility (TSF) failures and in anticipation of uprated guidelines and potentially legislation, Worsley Alumina Refinery Limited (WARL) decided to update previous dam break assessments conducted on their bauxite residue storage areas (BRDA). The previous assessments indicated a potential for residue and effluent to flow more than $30 \mathrm{~km}$ from the refinery boundary limits in the event of a dam break with liquefied residue flow. At the outset of the updated assessment, the importance of incorporating representative rheology into the dam break modelling was recognised and specific testing and analysis in this regard was commissioned. It was also decided that the dam break assessment without an associated semi-quantitative risk assessment to place the dam break in the correct perspective would not provide a true picture of the risks posed by the BRDAs to top management and insurers. Subsequently, the Global Industry Standard for Tailings Management has put out guidelines and draft guidance documentation stipulating that dam break assessments are mandatory, that these need to be based on credible data and assumptions, and that the assessments need to be supported by a semi-quantitative risk assessment.

This paper describes the updated dam break assessment prepared for WARL's BRDA5, located as indicated in Figures 1 and 2. It covers the geotechnical assessments to evaluate the susceptibility of the BRDA to liquefaction, a fault-event based semi-quantitative risk assessment, rheological testing and analysis, and 
probabilistic dam break liquefied flow modelling to determine potential inundation areas with confidence limits.

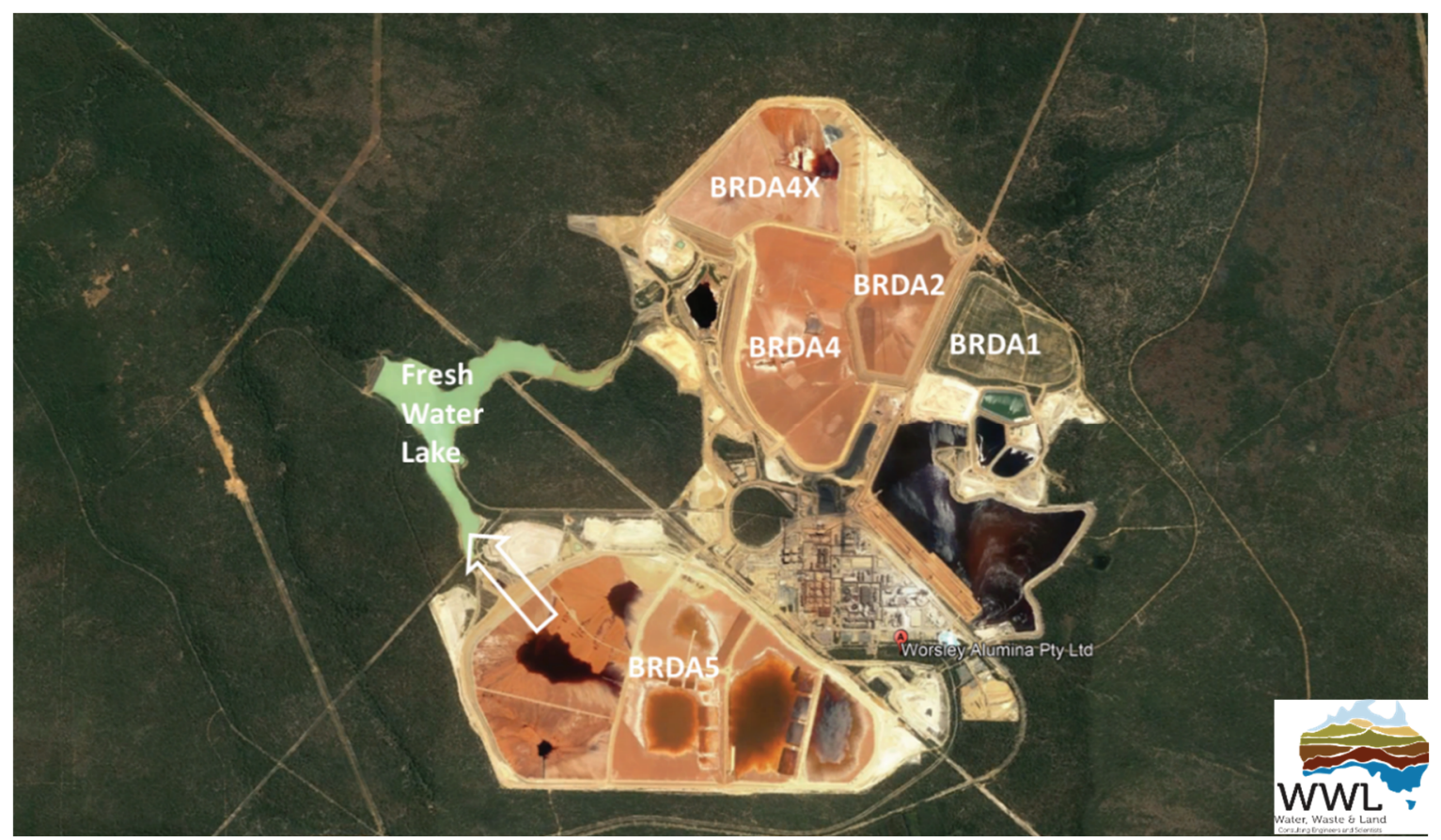

Figure 1 Layout of BRDAs at Worsley Alumina Refinery

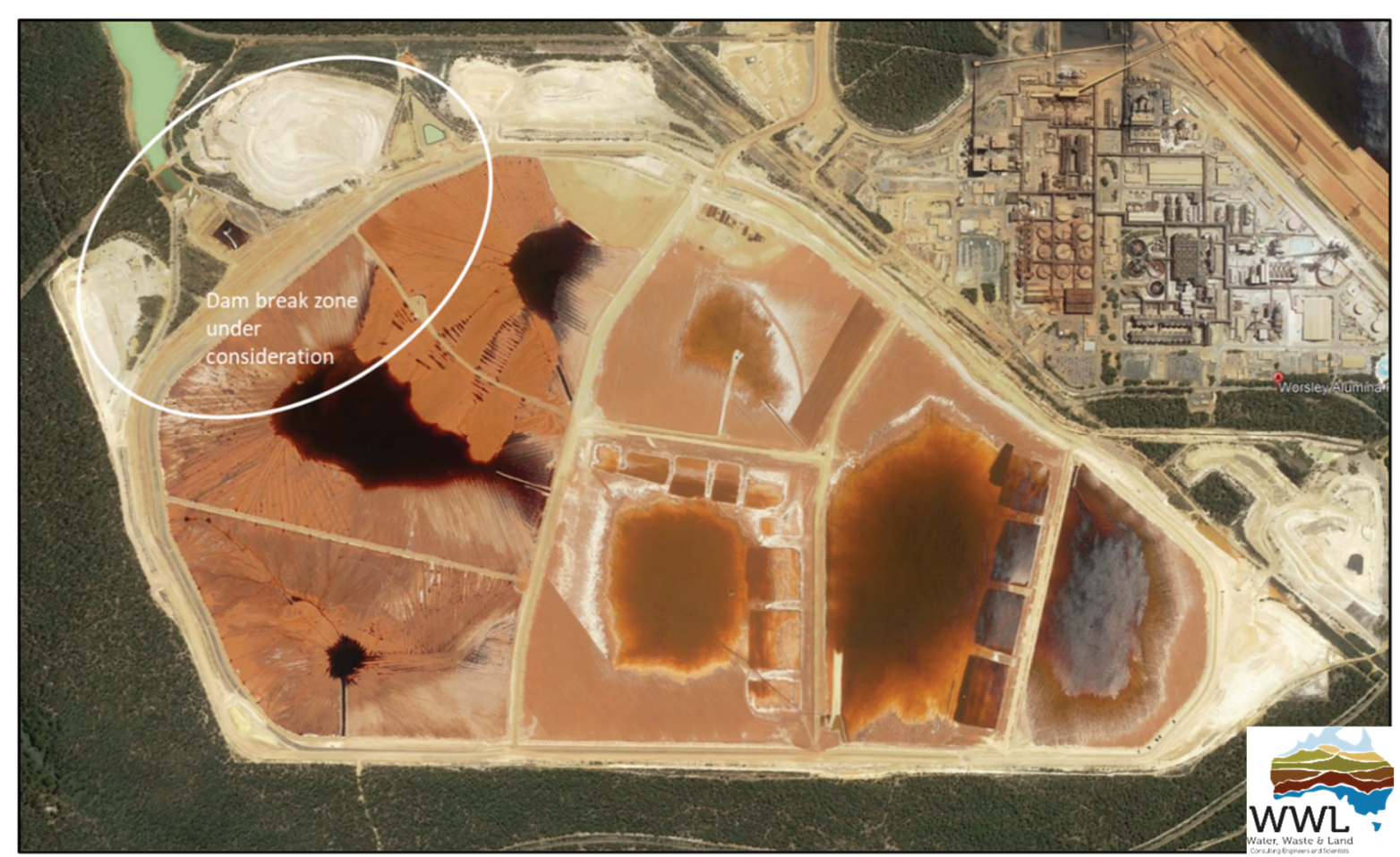

Figure 2 Layout of BRDA5 showing dam break zone under consideration

\section{Residue liquefaction assessment}

As with all mine tailings and industrial residue storage facilities, BRDA5 relies on external embankments to provide confinement to the mass stored. BRDA5 has been constructed across a valley to the south of the refinery. It has a compacted earthfill starter embankment with a maximum height of $22 \mathrm{~m}$. Raises above the starter embankment have been affected on an upstream construction basis with each upstream raise 
comprising a compacted earthfill embankment $5 \mathrm{~m}$ high with an external slope of 1:2.2, an internal slope of $1: 1.5$, and a crest width of $5 \mathrm{~m}$. From approximately the elevation of the starter embankment, the residue has been trafficked using amphirols to compress, dewater, and consolidate the residue in 0.9-1 m pour depths.

Removal of the support provided by the confining embankments will place the stored residue under increased shear stress with the potential for the applied shear stresses to exceed the peak shear strength of the residue. If the residue is contractive or if triaxial extension conditions are generated, there is potential for the residues to liquefy and flow. The dam break assessment therefore begins with geotechnical assessments to check for contractive behaviour.

\subsection{Available geotechnical information}

Geotechnical investigation work carried out on BRDA5 comprises:

- Drilling and sampling of BRDA5.

- Laboratory testing on undisturbed samples.

- Cone penetrometer testing with pore pressure measurements (CPTu) and dissipation testing with depth.

- Vane shear testing with depth.

Figure 3 shows the locations of borehole drilling, CPTu, and vane shear tests.

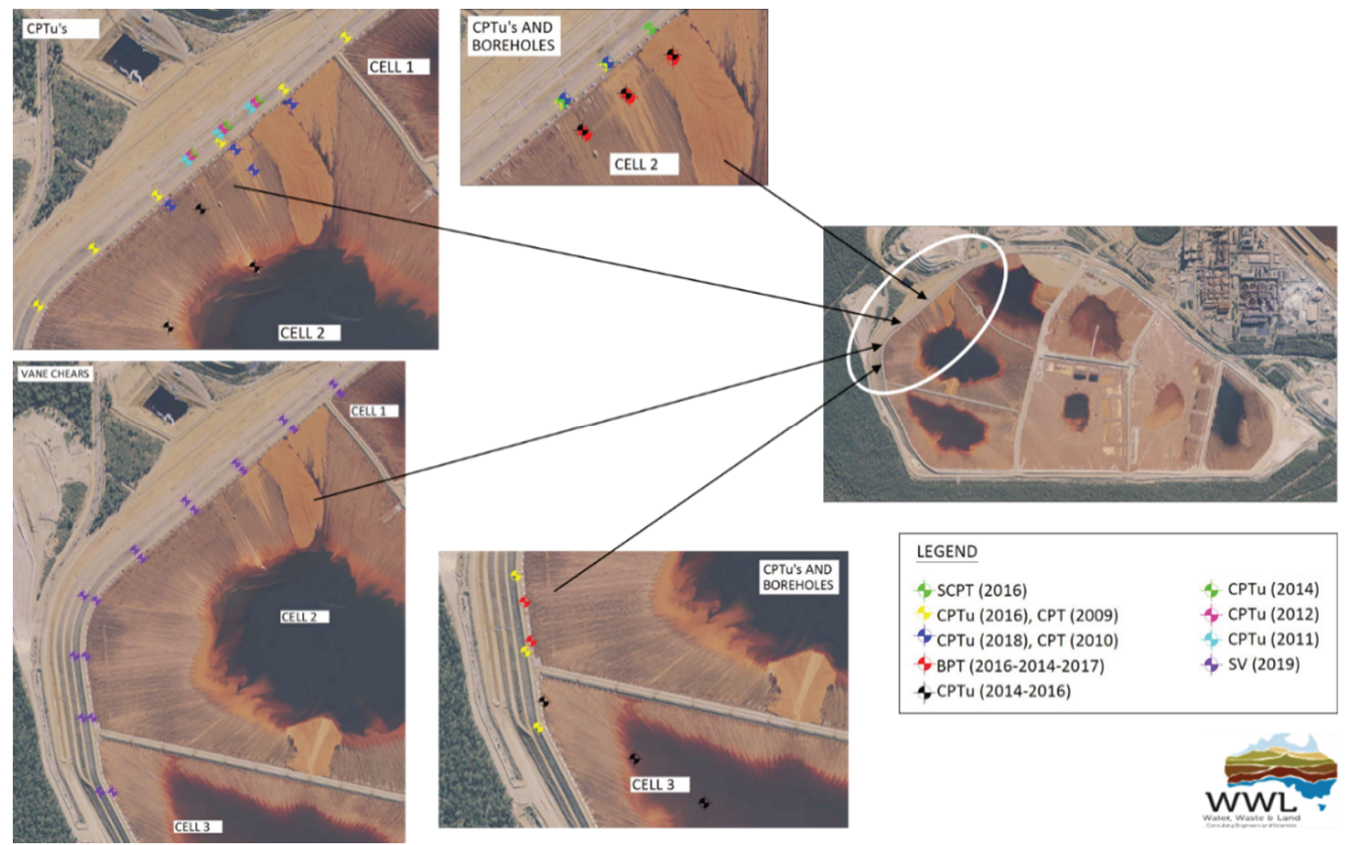

Figure 3 Locations of cone penetrometer testing with pore pressure measurements (CPTu), vane shears and boreholes within the dam break study zone on BRDA5

Table 1 shows the results of geotechnical indicator testing on the bauxite residue.

Table 1 Geotechnical indicators for the bauxite residue

\begin{tabular}{|c|c|c|c|c|c|c|c|c|}
\hline Parameter & $\begin{array}{l}\text { Specific } \\
\text { gravity } \\
-\end{array}$ & $\begin{array}{l}\text { Bulk unit } \\
\text { weight } \\
\left(\mathrm{kN} / \mathrm{m}^{3}\right)\end{array}$ & $\begin{array}{l}\text { Dry unit } \\
\text { weight } \\
\left(\mathrm{kN} / \mathrm{m}^{3}\right)\end{array}$ & $\begin{array}{l}\text { P80 } \\
(\mathrm{mm})\end{array}$ & $\begin{array}{l}\text { Clay } \\
(\%)\end{array}$ & $\begin{array}{l}\text { Liquid limit } \\
\text { (\%) }\end{array}$ & $\begin{array}{l}\text { Plastic limit } \\
\text { (\%) }\end{array}$ & $\begin{array}{l}\text { Plasticity index } \\
\text { (\%) }\end{array}$ \\
\hline Value & 3.313 & 21.97 & 16.78 & 0.093 & 24 & 33 & 24 & 8 \\
\hline
\end{tabular}

The results of the testing have been analysed to assess the potential contractiveness, brittleness and degree of cementation due to ageing of the residue. These assessments are set out in the following section. 


\subsection{Assessment of contractiveness of the residue}

An assessment of contractiveness begins with estimation of the critical state line. This has been determined from triaxial testing on residue samples reconstituted to densities that will produce contractive behaviour.

Figure 4 shows the triaxial stress paths and the critical state line.
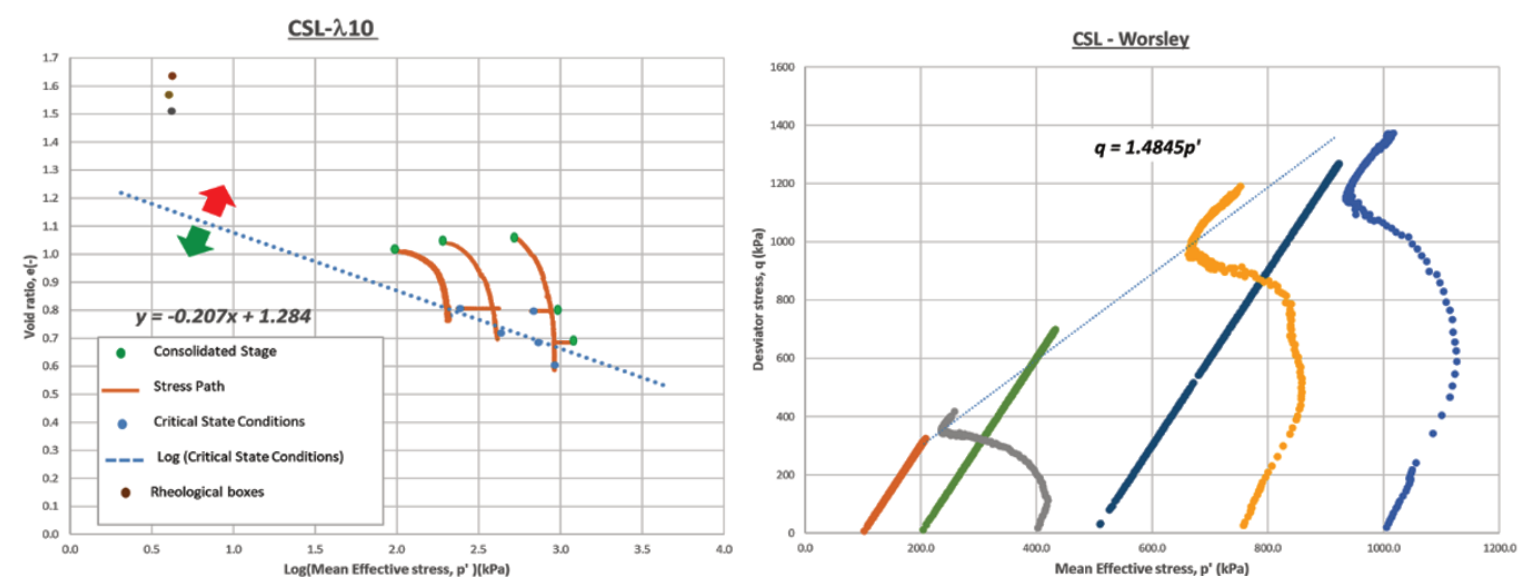

\begin{tabular}{|c|c|}
\hline \multicolumn{2}{|c|}{ Semi-log CSL } \\
\hline $\boldsymbol{\lambda} 10$ & 0.207 \\
\hline $\boldsymbol{\lambda e}$ & 0.090 \\
\hline $\boldsymbol{\Gamma}$ & 1.284 \\
\hline $\mathbf{M t c}$ & 1.485 \\
\hline
\end{tabular}

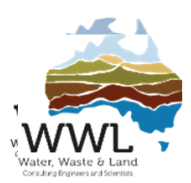

Figure 4 Critical state line for the bauxite residue from triaxial testing

Analysis of the CPTu testing was carried out using the method of Been and Jeffreys. Figure 5 shows plots of zones of contractive tailings based on the analyses. Figure 6 shows typical plots of the CPTu data applied to assess whether the residue is contractive, and Figure 7 shows the detail of the zone noted in Figure 5.

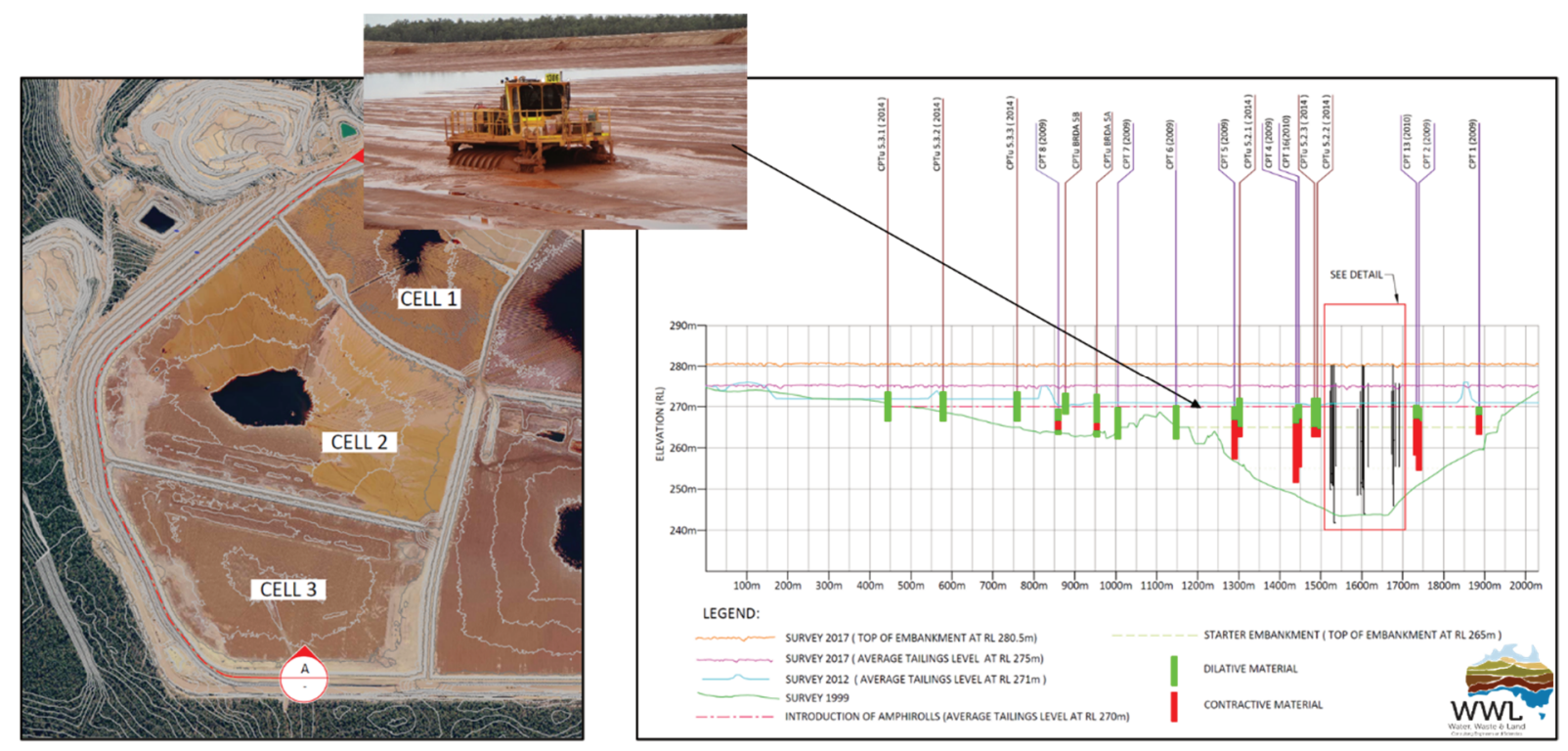

Figure 5 Zones of contractive residues based on CPTu testing 

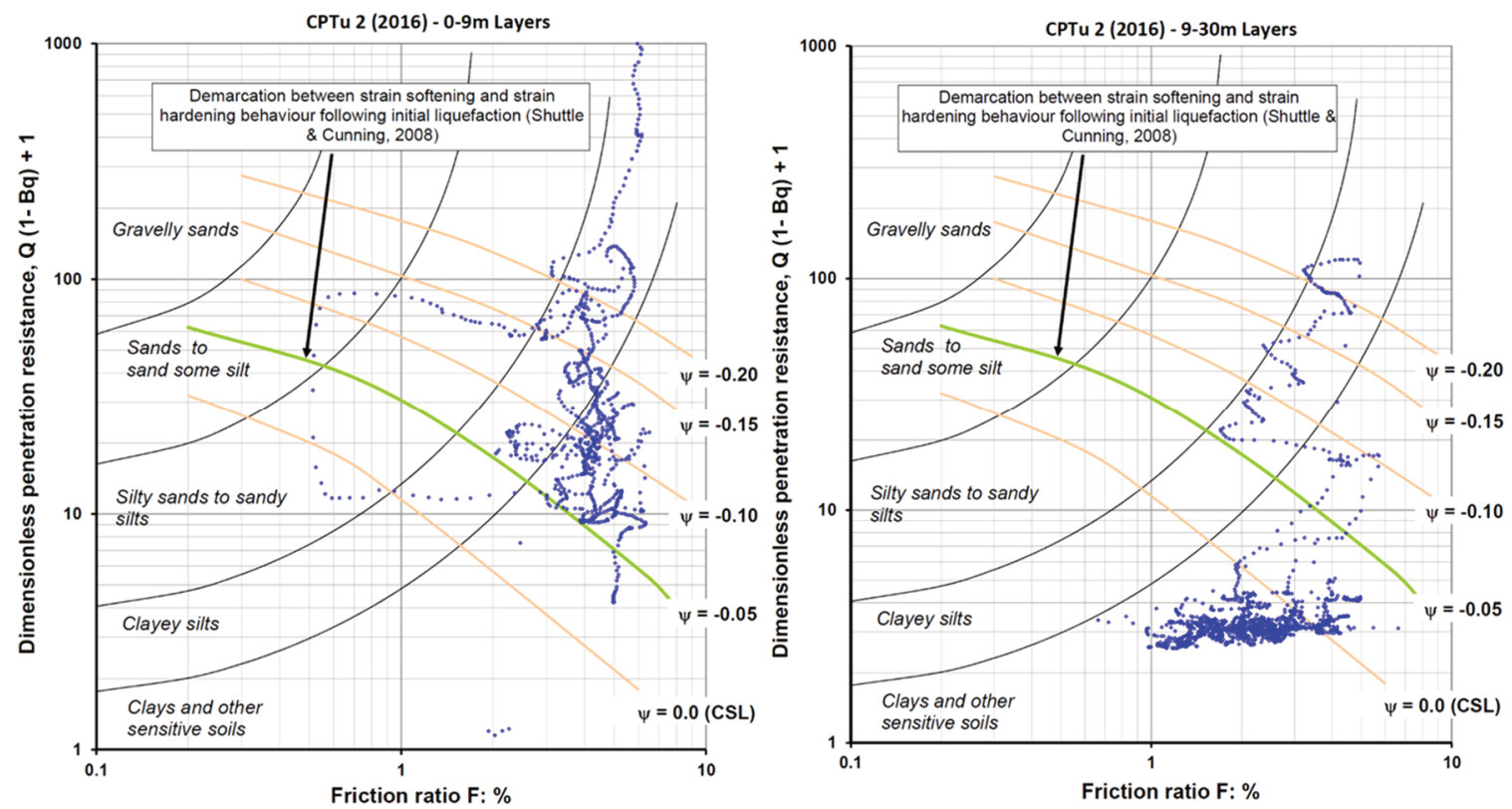

Figure 6 Evaluation of cone penetrometer testing with pore pressure measurements (CPTu) results with dilatant residue on the left and contractive on the right
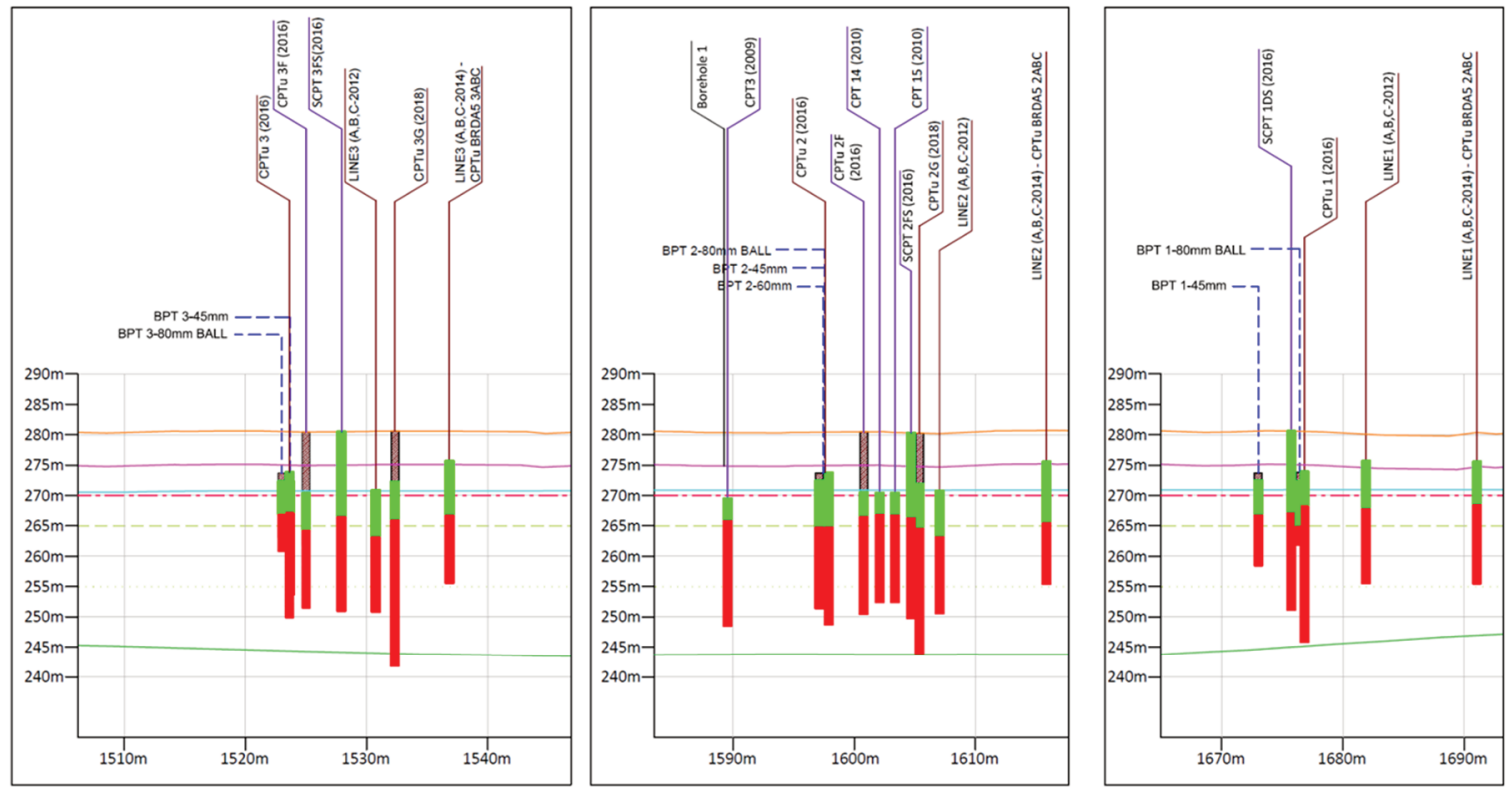

LEGEND:
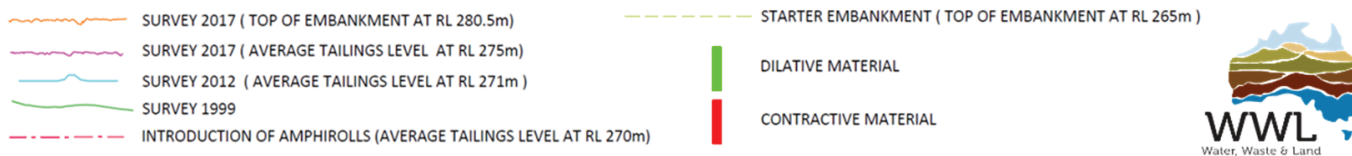

Figure 7 Contractive residues in the central valley area of BRDA5

It is evident that residues below the starter embankment also coincides with the elevation at which amphirolling with the equipment indicated in Figure 5 began. The fact that amphirolled residues do not show contractive behaviour suggests that only two potential liquefaction scenarios merit consideration:

- Liquefaction flow failure of a newly deposited layer of residue at the top of BRDA5 should the support of the uppermost confining embankment be removed.

- Liquefaction flow failure of the mass of tailings below the starter embankment should the support of the starter embankment be removed. 


\subsection{Assessment of representative undrained shear strength}

Triaxial as well as direct simple shear testing has been carried out on undisturbed samples of residue producing estimates of the peak (yield) as well as residual (critical) undrained shear strength and estimates of the brittleness index, IB as indicated in Table 2 below. Indicated in Table 3 are the results of cyclic undrained shear strengths from direct simple shear testing.

Table 2 Undrained shear strength data from triaxial shear testing

\begin{tabular}{|c|c|c|c|c|c|c|c|c|}
\hline \multicolumn{9}{|c|}{ Lab test (triaxial) - CKOU triaxial - Su(yield)/s'v - BH1 - BRDA 5} \\
\hline $\begin{array}{l}\text { Depth } \\
\text { (m) }\end{array}$ & $\begin{array}{l}q^{\prime}(\text { yield) } \\
(\mathrm{kPa})\end{array}$ & $\begin{array}{l}q^{\prime}(\text { critical) } \\
(\mathrm{kPa})\end{array}$ & $\begin{array}{l}\text { Su(yield) } \\
(\mathrm{kPa})\end{array}$ & $\begin{array}{l}\text { Su(critical) } \\
(\mathrm{kPa})\end{array}$ & $\begin{array}{l}\text { s'v } \\
\text { (kPa) }\end{array}$ & Su(yield)/s'v & Su(critical)/s'v & IB \\
\hline 4 & 214.0 & 198.0 & 107.0 & 99.0 & 188.0 & 0.57 & 0.53 & 0.07 \\
\hline 9 & 210.0 & 187.5 & 105.0 & 93.8 & 228.0 & 0.46 & 0.41 & 0.11 \\
\hline 15 & 291.0 & 265.0 & 145.5 & 132.5 & 365.0 & 0.40 & 0.36 & 0.09 \\
\hline 21 & 411.0 & 393.0 & 205.5 & 196.5 & 542.0 & 0.38 & 0.36 & 0.04 \\
\hline 25 & 497.0 & 420.0 & 248.5 & 210.0 & 584.0 & 0.43 & 0.36 & 0.15 \\
\hline
\end{tabular}

Table 3 Cyclic undrained shear strength data from direct simple shear testing

\begin{tabular}{|c|c|c|c|c|}
\hline \multicolumn{5}{|c|}{ Lab lest (cyclic) - CDSS cyclic direct simple shear - Su(post-cyclic)/s'v - BH1 - BRDA 5} \\
\hline $\begin{array}{l}\text { Depth } \\
\text { (m) }\end{array}$ & $\begin{array}{l}\text { Su(cyclic 3\% strain) } \\
\text { (kPa) }\end{array}$ & $\begin{array}{l}s^{\prime} v \\
\text { (kPa) }\end{array}$ & Su(cyclic)/s'v & IB \\
\hline 4 & 37.0 & 100.0 & 0.37 & 0.65 \\
\hline 9 & 62.5 & 250.0 & 0.25 & 0.40 \\
\hline 15 & 106.6 & 410.0 & 0.26 & 0.27 \\
\hline 21 & 167.4 & 540.0 & 0.31 & 0.18 \\
\hline
\end{tabular}

\subsection{Assessment of the brittleness of the residue}

Sadrekarimi (2014) analysed the data from liquefaction failures and developed the plots indicated in Figure 8 for peak (yield) undrained strength, and in Figure 9 for residual (critical) undrained shear strength. The squares indicate historical liquefaction failures. The data from the triaxial testing indicates that the residue is well outside of the zone of liquefiable materials. 


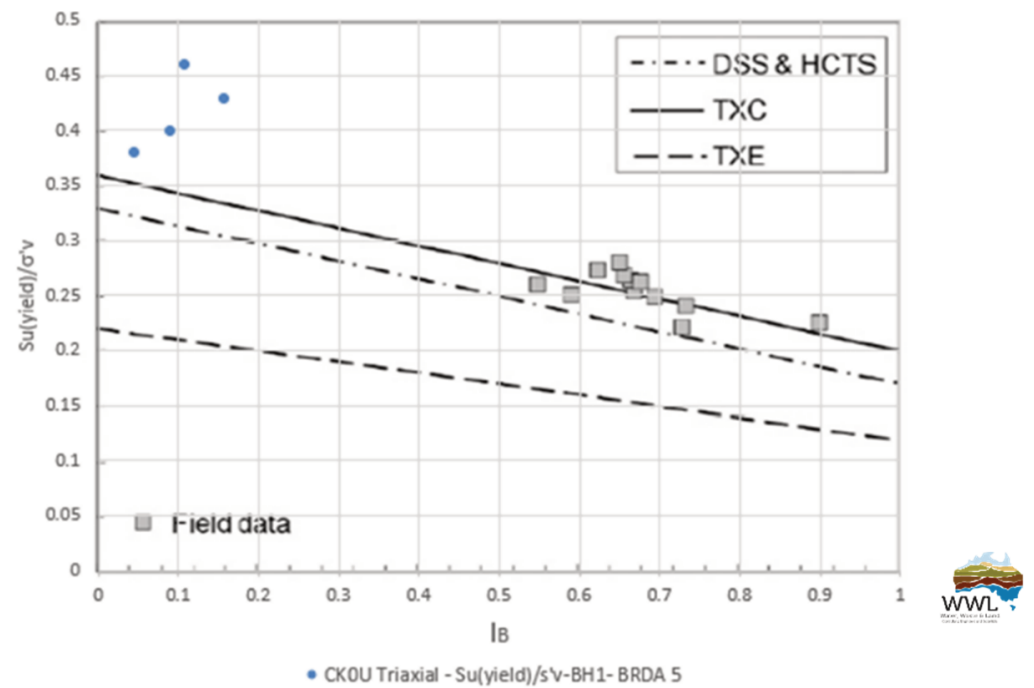

Figure 8 Plots of peak undrained shear strength versus brittleness index superimposed on Sadrekarimi's plots

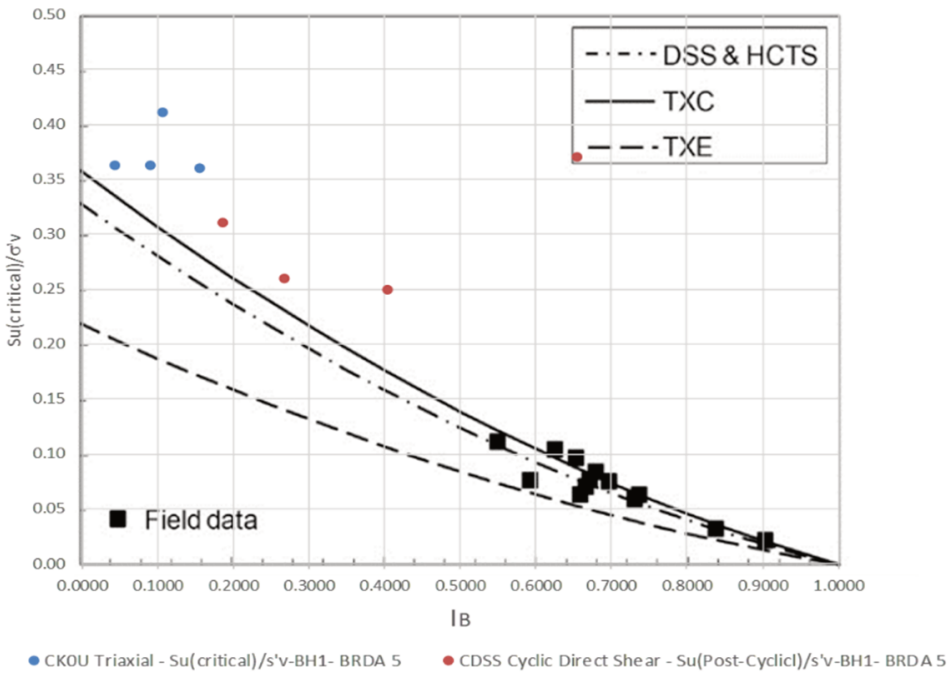

Figure 9 Plots of residual undrained shear strength versus brittleness index superimposed on Sadrekarimi's plots

\subsection{Assessment of the cementing in the residue}

Ageing of the residue has been found to result in a degree of cementing.

An assessment of the cementing behaviour of the residues as a result of chemical reactions has been carried out. Freshly deposited residues show uncemented behaviour. However, as shown in this study, residues in BRDA5 have a cementing characteristic, which is likely to be due to the effect of caustic on the residue particles.

It is necessary to assess the behaviour of residues under seismic excitation and the resistance due to chemical bonds between particles to find out if this extra chemical bond will continue to provide good resistance in the case of seismic event.

The cementing assessment was carried out using methods of:

- Dusan Berisavljevic (Jan 2018) for SCPTu (pers. comm. January 2018).

- Robertson (2016) for CPTu.

- Schneider et al. (2012) for CPTu. 
Estimation of the small strain rigidity index $\mathrm{K}_{G}^{*}$ using the Dusan Berisavljevic and Robertson (2016) methods uses the shear wave velocities from the SCPTu to establish the relationship between $G_{0} / q_{n}(I G)$ and $Q_{t n}$, as these recede where $\left(G_{0}\right)$ is the small strain stiffness, $q_{n}$. is the cone resistance, and $Q_{t n}$ is the normalised cone resistance. The bonding tends to increase the small strain stiffness $\left(G_{0}\right)$ significantly more than it increases the strength of a soil (reflected in $q_{n}$ ). Values of $K_{G}^{*}$, which is the slope of the $Q_{t n}$ versus IG line, that are above 300 represent cemented materials, and values of $K_{G}^{*}$ below 100 represent uncemented materials.

An assessment of the effects of cementing on the contractive/dilative behaviour has also been carried out also using the method of Robertson (2016) and Schneider et al. (2012) for CPTu data (as opposed to SCPTu data used above) where the effective excess porewater pressure index $U_{2}$ is used. Positive $U_{2}$ values tend to reflect large strain contractive behaviour and negative $U_{2}$ values tend to reflect large strain dilative behaviour.

This approach was applied to the tests CPTu 1, CPTu 2, CPTu 2F, CPTu 3 and CPTu 3F. These are recent tests located at northwestern embankment where the flow slide is modelled.

Figure 10 shows the results of the ageing analysis for SCPT 1DS, SCPT 2FS and SCPT 3FS based on Dusan Berisavljevic's approach and Figure 11 shows the results for CPT1 based on Robertson (2016) and Schneider et al. (2012) approaches.

Cementing assessment results presented in this section show cementing behaviour and the effect of this behaviour is generally evident over the full depth of the residues. The results also show dominance of materials in transitional dilative category. This is likely to be a contributor to the locations of the plots in Figures 8 and 9.

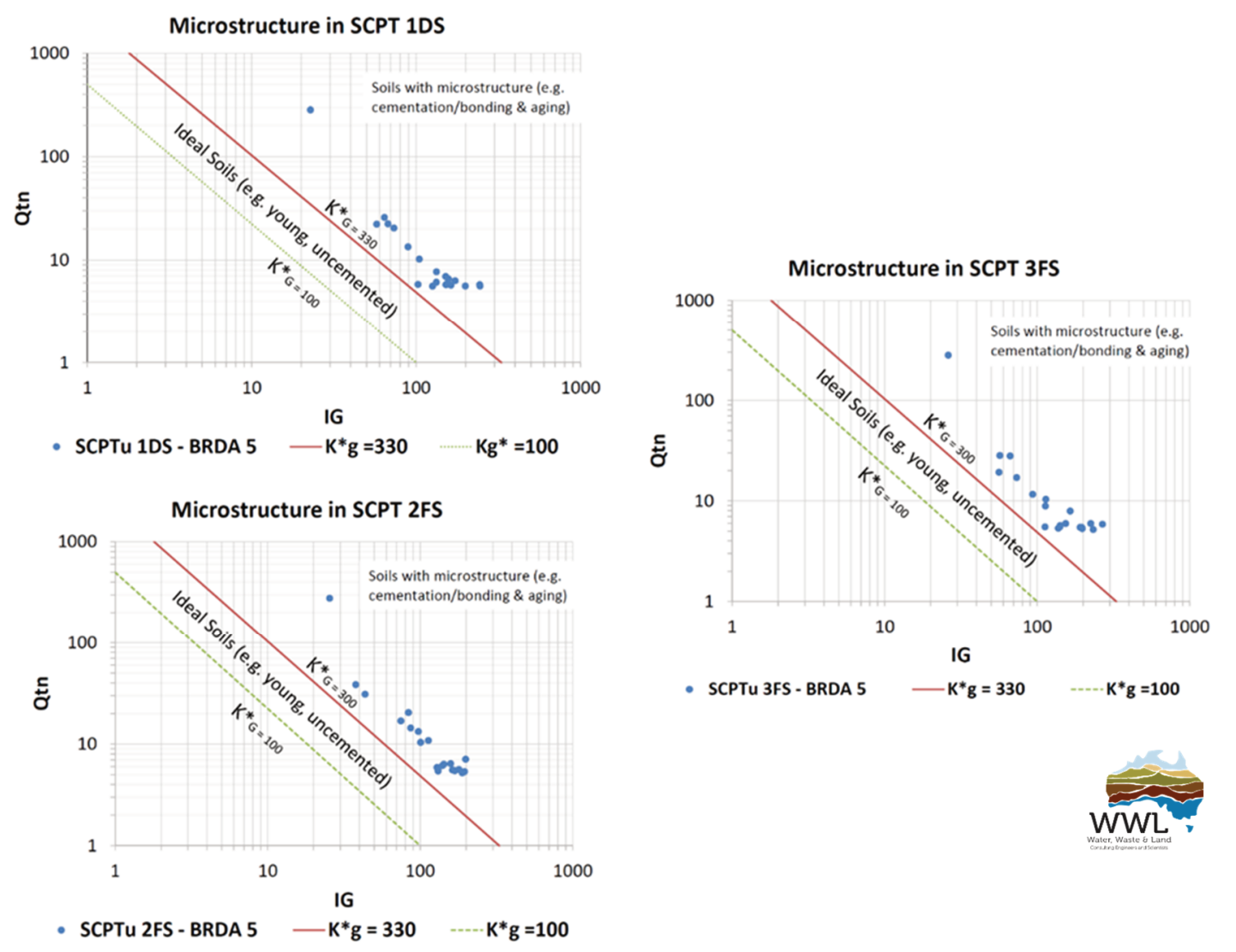

Figure 10 Cementing assessment for SCPT 1DS, SCPT 2FS and SCPT 3FS 


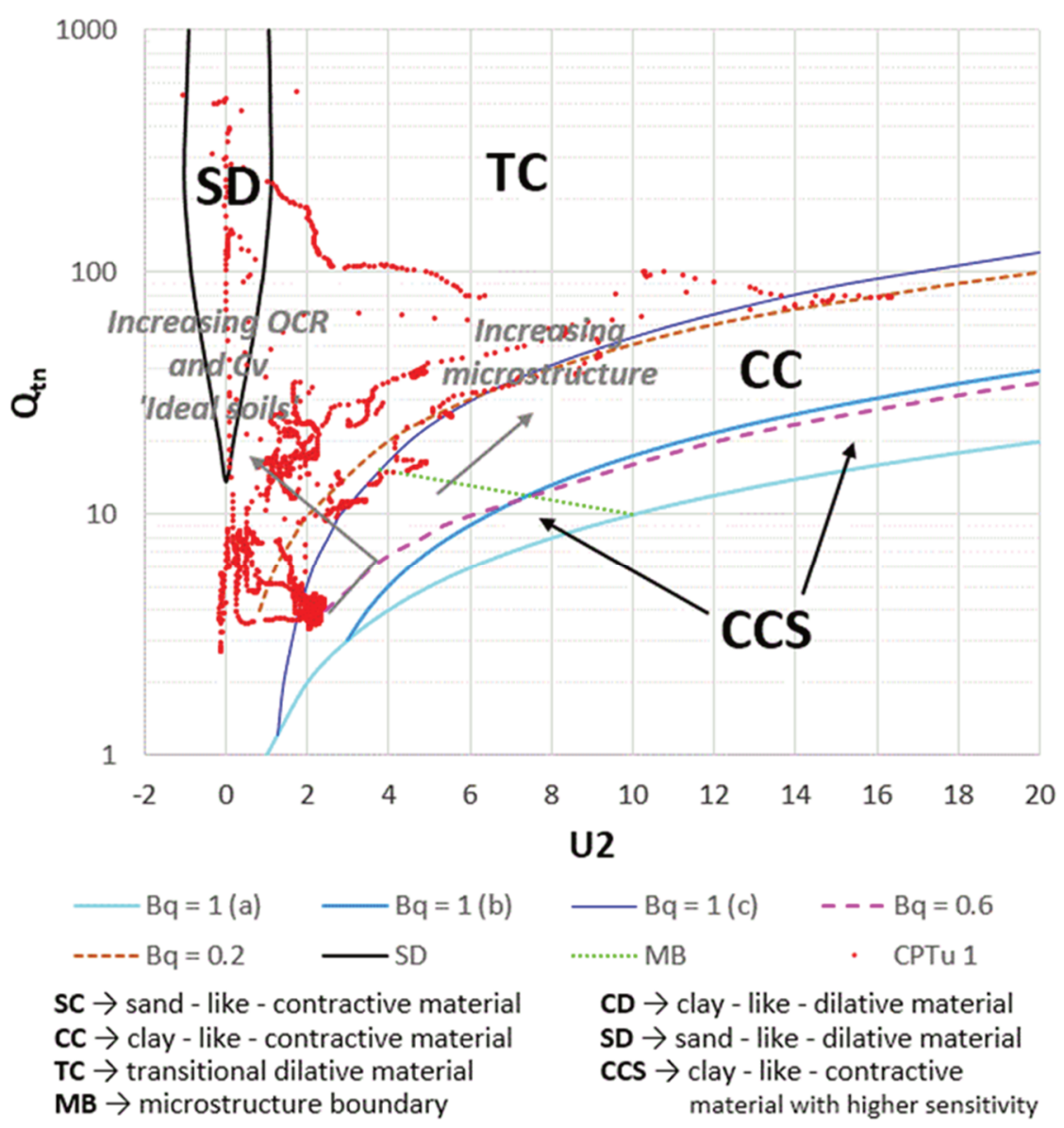

Figure 11 Cementing assessment for cone penetrometer testing with pore pressure measurements (CPTu) 1

\subsection{Conclusions from geotechnical assessments}

It is evident from the information presented that there are two zones of concern within BRDA5. One is the topmost layer of residue immediately following a pour and before amphirolling benefits have taken effect. For these materials if the confining embankment were to be eroded away by rainfall or leaks from a pipe burst there is potential for liquefied residue to flow down to the freshwater lake.

The second zone is below the level of the starter embankment. If the support of the starter embankment were to be removed as a result of slope failure or severe erosion, there is potential for liquefied residue to flow to the freshwater lake.

\section{Assessment of the probability of a dam break and a flow slide}

Assessment of the probability of a dam break and flow slide has been carried out using a fault-event analysis process in which:

- A fault assessment organised into fault trees in which top faults or triggers for a dam break are broke down into root causes. The fault tree allows for combinations of faults which need to occur simultaneously and faults which may occur independently and facilitates the Boolean algebra calculations of probability.

- The focus has been placed on five dam break triggers each of which is capable of removing support to potentially liquefiable residue with the potential for liquefaction flow failure:

- Static instability leading to slope failure.

- Seismic instability leading to slope failure. 
- Overtopping leading to erosion of the confining embankment and slope failure.

- Failure of a buried structure leading to piping erosion and slope failure.

- Geotechnical piping leading to erosion and slope failure.

Examples of the above five mechanisms are:

- Static slope instability, e.g. Mt Polley (2012), Samarco (2015), Brumadinho (2019).

- Seismically-induced slope instability, e.g. El Cobre (1965).

- Overtopping, e.g. Merriespruit (1994).

- Failure of a buried structure, e.g. Stava (1985).

- Geotechnical piping, e.g. Bafokeng (1974).

The fault-event tree is a semi-quantitative approach in that, where practical, probabilities are calculated or modelled but otherwise are assigned based on evaluation of the circumstances.

Figures 12, 13, and 14 show a selection of the fault trees developed for BRDA5:

- Figure 12 shows the fault tree for slope failure under static conditions. The round helmet gates below each fault are 'Or' gates where faults on the same level are additive, i.e. occur independently, the triangles are indicative of a further fault tree below the fault, and the circular gates represent the base fault.

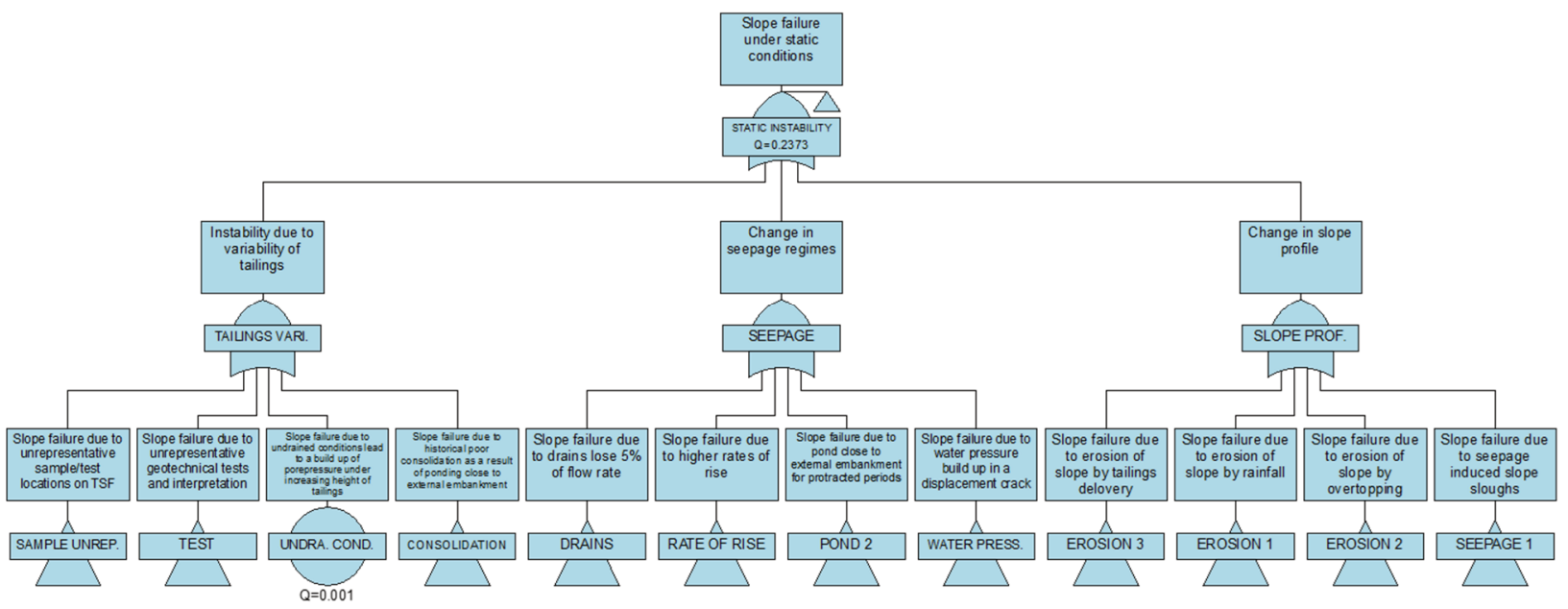

Figure 12 Fault tree for slope instability under static conditions

- Figure 13 shows the fault tree below the fault for drain malfunction leading to a change of flow rate of $5 \%$. The square helmeted gates represent 'AND' gates where the probabilities are multiplicative, i.e. need to occur simultaneously. 


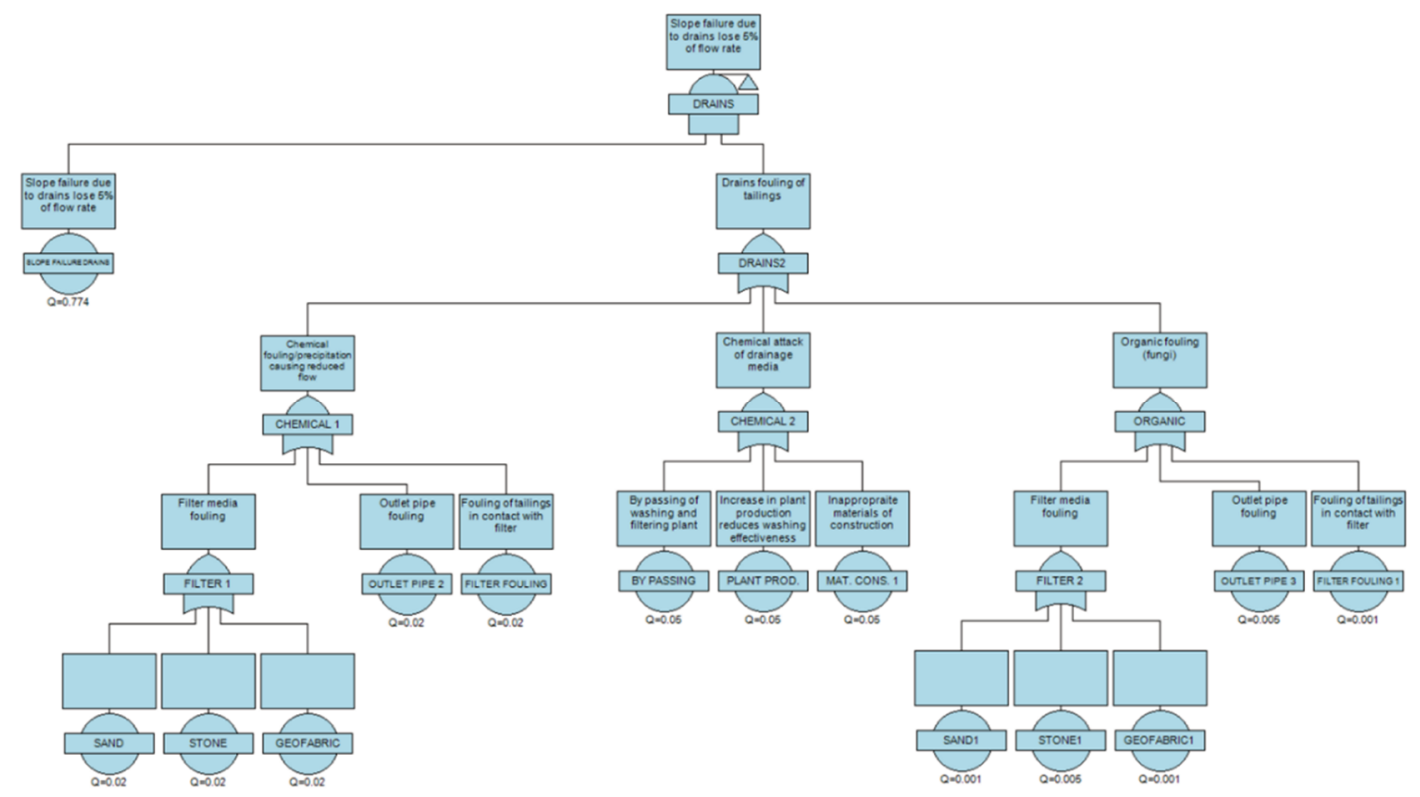

Figure 13 Fault tree for drain flow reduction by $5 \%$

Figure 14 shows the top fault tree where the probability of liquefaction flow is calculated. Two branches are considered, one fault for removal of support to the residues through static failure and one fault through seismic failure. These probabilities are additive. Below each of these is consideration of the probability of liquefaction given removal of support. These probabilities are multiplicative. Below these faults are considerations of the faults that could lead to removal of support to the residue and consideration of the shear stress conditions applied to the residues as a result of this. After taking all of the faults into consideration, including the probability that observation and monitoring is effective in arresting the progression to the flow slide based on a failure modes and effects analysis (FMEA) with refinery personnel, the probability of liquefaction flow is estimated as 0.072 which is equivalent to $7.84 \mathrm{E}-6$ per year with the highest contributing risks related to slope failure under static and seismic conditions, as well as the probability of triaxial extension causing liquefaction once support to the residue is removed.

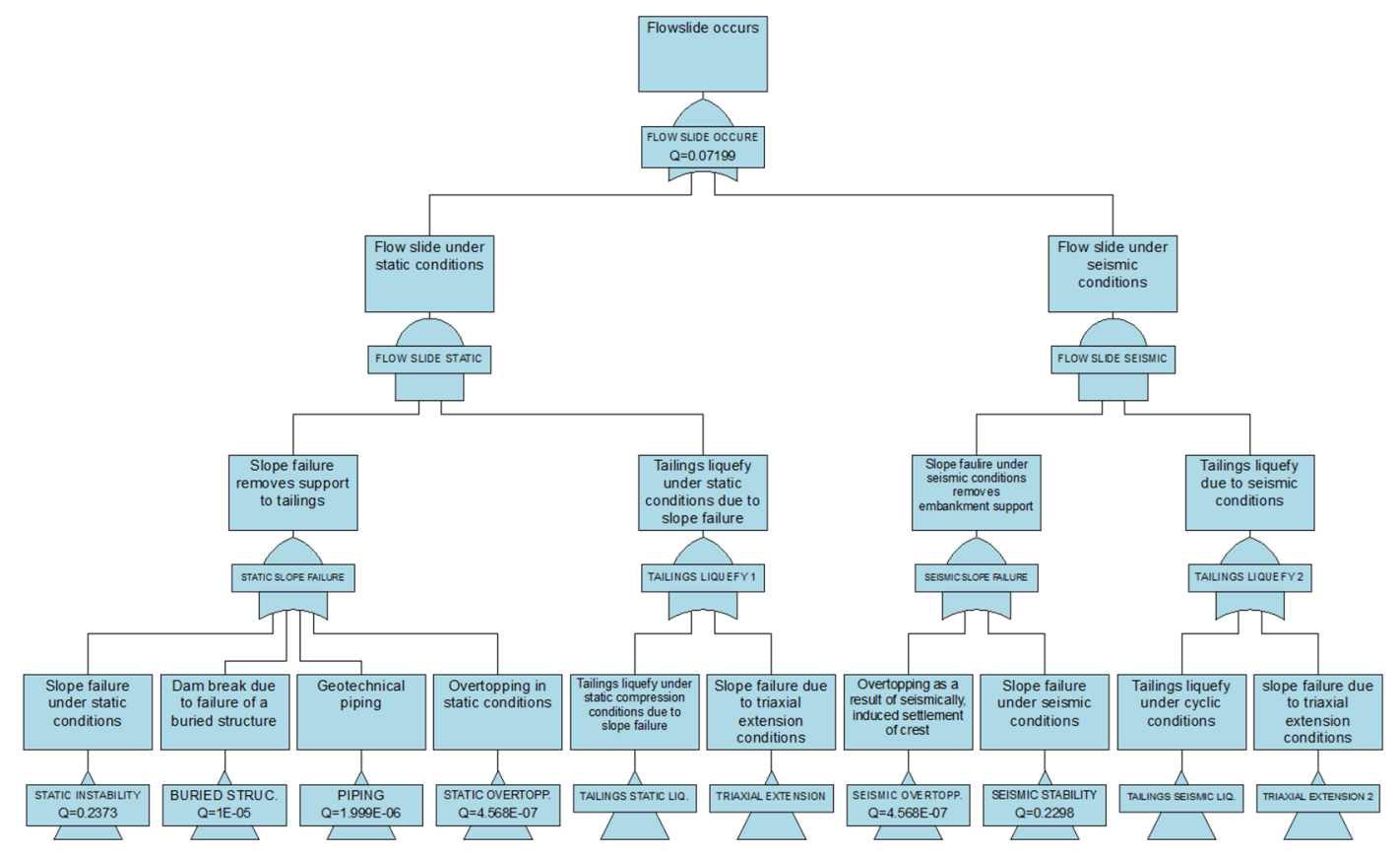

Figure 14 Fault tree for liquefaction 
To assess the implications of a liquefaction flow failure the probability is carried forward into an event tree analysis which enables the propagation of probabilities to environmental damage, loss of production, and loss of life taking into consideration the flow geometry as determined by the flow slide assessment. The event tree is populated by considering events that may transpire following initiation of a flow slide. These events are assessed through a series of questions:

- Will there be environmental damage? A probability of 1 has been assigned to this since, while the flow slide within the mine property would flow over disturbed ground into the freshwater lake, depending on the scale of the flow slide, the flow slide may also induce spillage from the dam that will have been contaminated by the flow slide. The probability remains at 7.84E-6.

- Will there be a plant stoppage and therefore a production loss? This probability is taken as 1 since it is likely that regulators will work to suspend operations while an investigation into the circumstances leading to the dam break is conducted. The probability remains at 7.84E-6.

- Are there people present at the failure or in the flow path? A probability of 1 has been assigned to the area at the dam break this since, while the operators are present on the TSF only during the day shift, people are likely to be present around the failure zone attempting to stem failure development. Beyond the failure zone, the probability of people being present on or below the freshwater lake is taken into consideration.

- Will there be mortalities? The probability for this event has been taken as 0.5 on the basis that if there are people present in the flow path, there is a $50 \%$ probability that they may be killed.

Table 4 presents a summary of the probabilities.

Table 4 Probabilities of mortality and major environmental damage

\begin{tabular}{ll}
\hline P[Mortality between BRDA 5 and FWL] & $4.05 \mathrm{E}-06$ \\
P[Mortality FWL failure due to spill] & $4.14 \mathrm{E}-06$ \\
P[Mortality FWL failure due to tsunami $]$ & $3.97 \mathrm{E}-06$ \\
P[Major environmental and infrastructure damage] & $7.84 \mathrm{E}-06$ \\
\hline
\end{tabular}

The results of the fault-event assessment have enabled WARL to achieve a significant reduction in insurance premiums related to BRDA5.

\section{$4 \quad$ Dam break assessment}

The probabilities in Section 3 take into consideration the extent of inundation to estimate the people at risk. For this modelling of the dam break and liquefaction flow slide has been carried out. Two scenarios have been considered:

- Rainy day scenario where the dam break is precipitated by overtopping or piping erosion causing removal confinement of the residue.

- Sunny day scenario where the dam break is precipitated by slope failure due to slope instability.

The following potential results for have been considered:

- Discharge of water with limited removal of residue while erosion of the embankment takes place. In the rainy day scenario, this is a result of overtopping due to excessive rain causing a flood on the BRDA. In the sunny day scenario, this is a result of poor management of the supernatant pond on the BRDA. Volumes of water are lower in the sunny day scenario.

- Liquefaction flow of the residue with the rheology of the liquefied residue influenced by the overflowing water.

- Slope slump with limited flow. 
While all of the situations have been evaluated in the assessment, in this paper, only the overtopping flood assessment (water) and the liquefaction flow failure under rainy day conditions are presented in this paper.

\subsection{Overtopping flood assessment}

In the overtopping assessment where water is discharged over the crest, the following assumptions have been made in modelling to determine the flood inundation area, indicated in Figure 15:

- The probable maximum flood (PMF) occurs on the BRDA.

- The PMF occurs in the contributing catchments to the freshwater lake and the river downstream of the lake.

- The freshwater lake is at full supply level, i.e. water is level with spillway invert.

Checks have been made to verify that:

- The freshwater lake spillway is able to pass the PMF.

- The high water level in the freshwater lake is below the crest of the fresh water lake embankment.

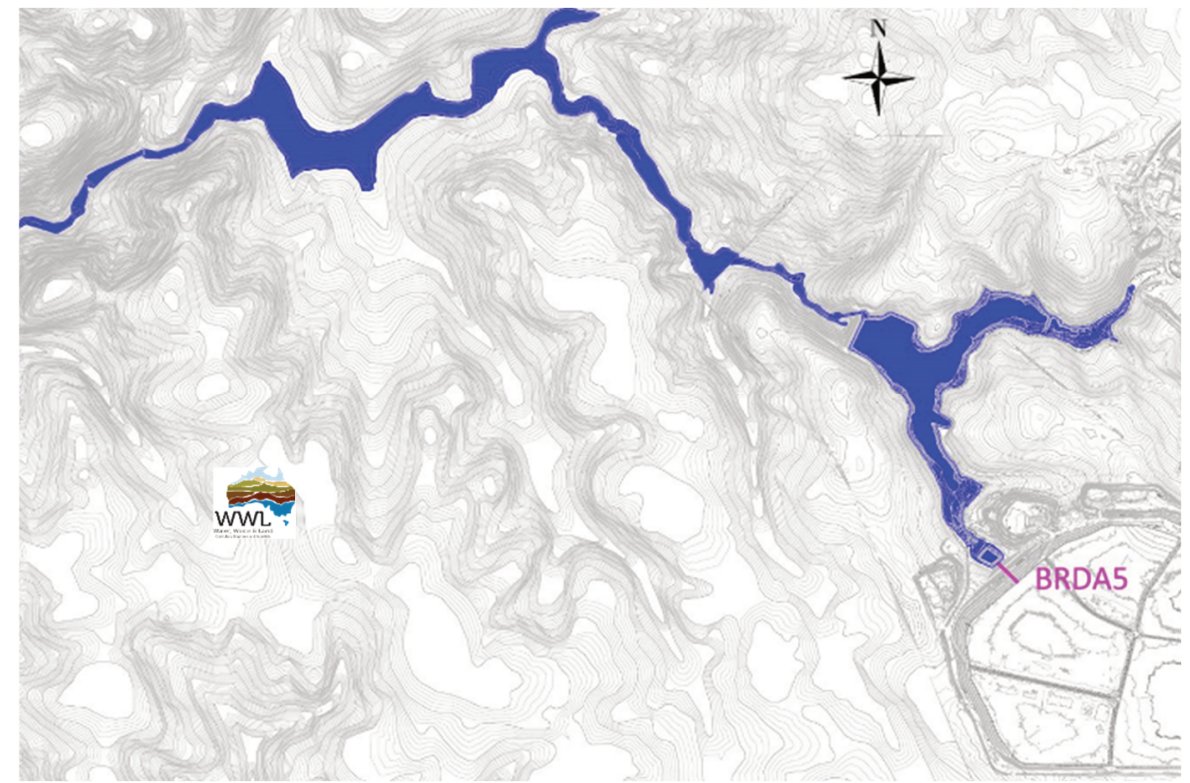

Figure 15 Flood inundation area from overtopping of BRDA5 and the freshwater lake

It is evident from Figure 15 that if the freshwater lake is at full supply level when the flood occurs, there is potential to disperse contaminated water well beyond the WARL boundary under PMF flood conditions.

The subsequent sections of the paper focus on the flow of liquefied residue.

\subsection{Liquefaction flow profile}

In liquefaction flow, generally one of two flow profiles result depending on the slope of the terrain and the extent to which this is able to contribute potential energy to the flow. These are indicated in Figure 16, which slows the situation for shallow sloping terrain and in Figure 17, which shows a flood wave progressing down the flow path. At BRDA5, the geometry in Figure 16 is most likely. 


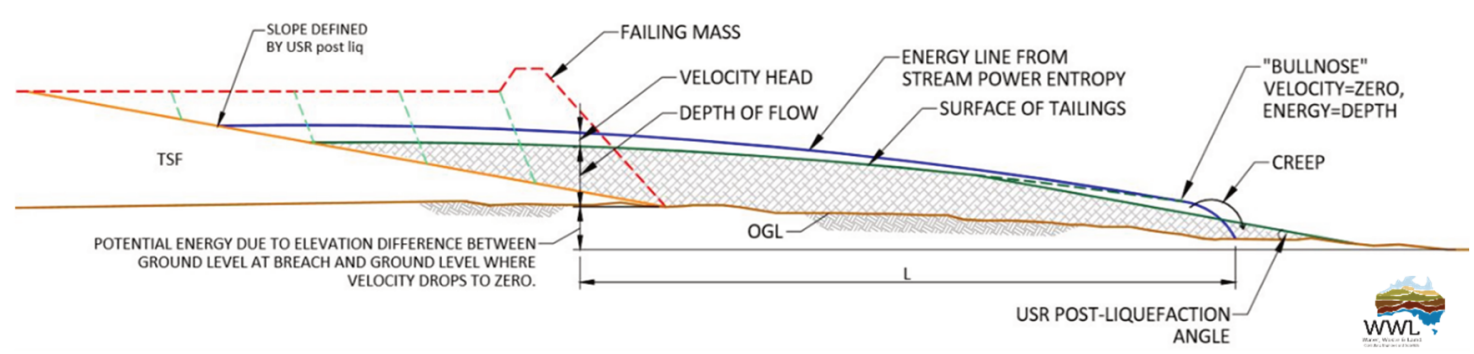

Figure 16 Flow slide geometry on shallow sloping ground

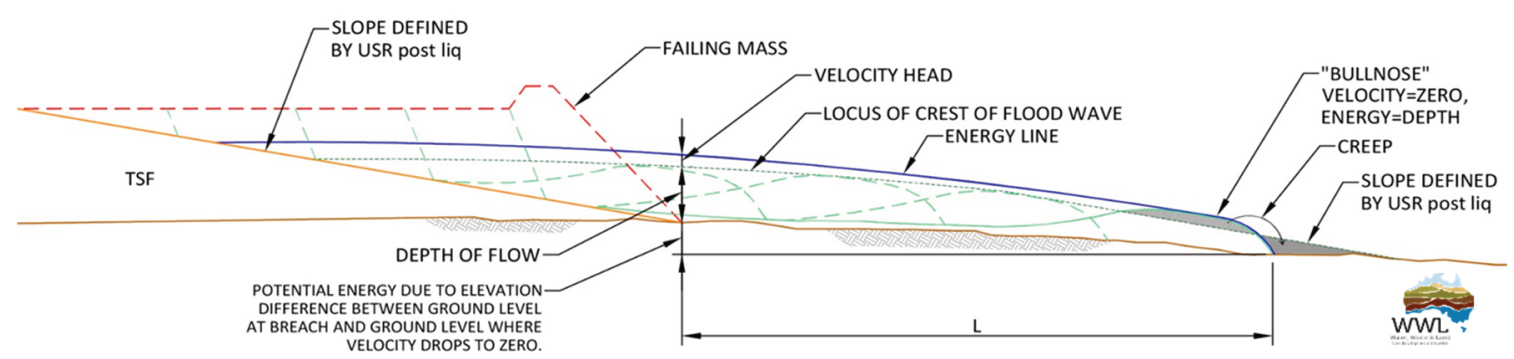

Figure 17 Flow slide advancing wave geometry on steeply sloping ground

\subsection{Key factors determining liquefaction flow inundation width and length}

The following factors are key in determining the inundation area:

- The outflow hydrograph since this sets initial energy level, velocity, and depth of flow.

- The rheology of liquefied slurry and specifically the influence of:

- Viscous and frictional forces within the slurry.

- Manning at low Reynolds numbers.

- Manning of viscous slurry.

- The natural channel geometry:

- Gradient.

- Shape (steep or shallow sides).

- Manning coefficients which will be influenced by:

- Channel roughness.

- Obstacles in channel

$\circ$ Meandering.

Estimation of the outflow hydrograph and the rheology are described as follows.

\subsection{Estimation of the outflow hydrograph of the liquefied residue}

The transition from the sedimented residue which is effectively a porous solid to a flowing mass is complex and not well understood at present. It seems clear, however, based on observations of past failures, that blocks or slides of residue are released with liquefaction occurring at the bases of the blocks due to stress conditions being a maximum at this location. While the material at the base of the block may liquefy, the stress levels higher up in the residue mass may not have been pushed over the peak shear stress and these materials will likely remain as porous solids for the duration of the period leading up to movement of the block. 
Estimation of the outflow hydrograph of the liquefied residue therefore needs to take into consideration the Newtonian mechanics that will regulate the movement of the residue mass. It is likely that two key geotechnical parameters will strongly influence the rate and extent of these movements. These are:

- USRpeak - since this will determine the velocities of moving blocks or wedges under gravity.

- USRpost liquefaction - since this will determine:

- The angle of the final wedge or the angle of the base of each block.

- The outflow volume.

\subsection{Truncated cone assumption}

To estimate the outflow hydrograph of the liquefied residue, an assumption of a cone-shaped residual crater has been made. Within the cone, a series of wedges or blocks is assumed to fail sequentially and at a speed determined by Newtonian mechanics. The cone assumptions are summarised in Figure 18.

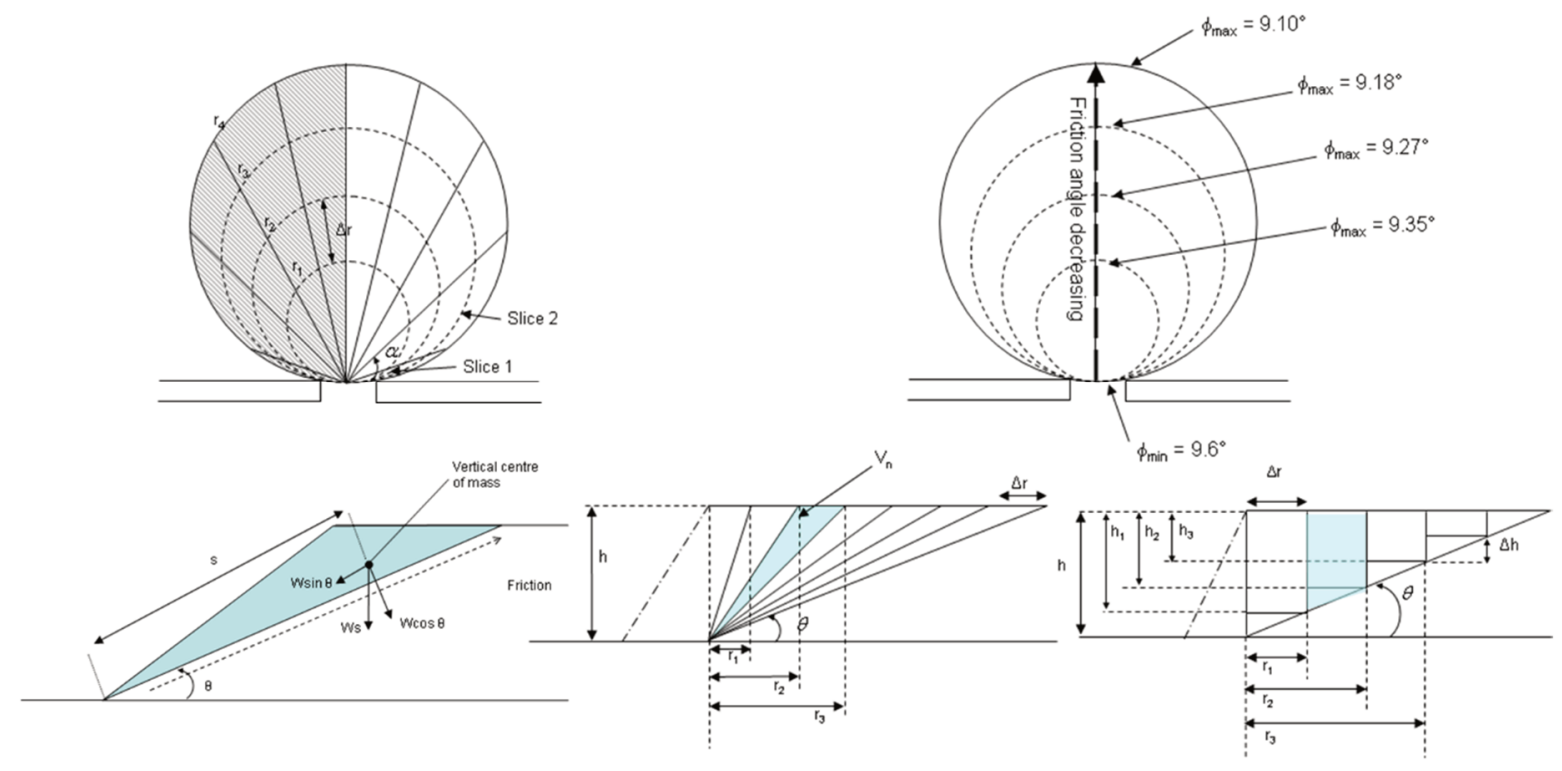

Figure 18 Truncated cone geometry

Three alternative geometries of wedges or blocks are considered, as illustrated in Figure 19, and the alternative with the highest peak is selected. The outflow hydrographs associated with the alternatives are indicated in Figure 19.

Alternative 1
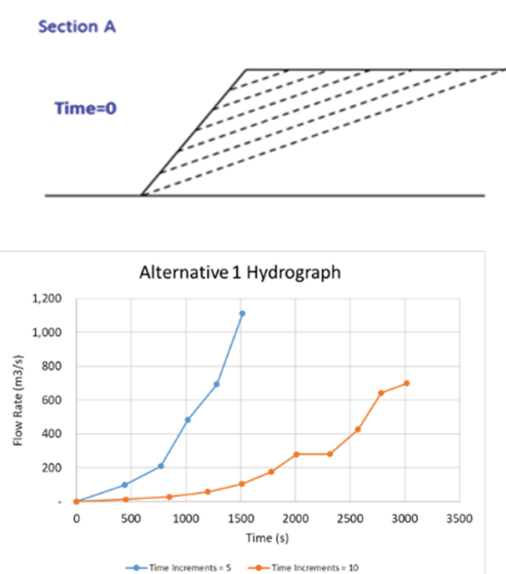

Alternative 2
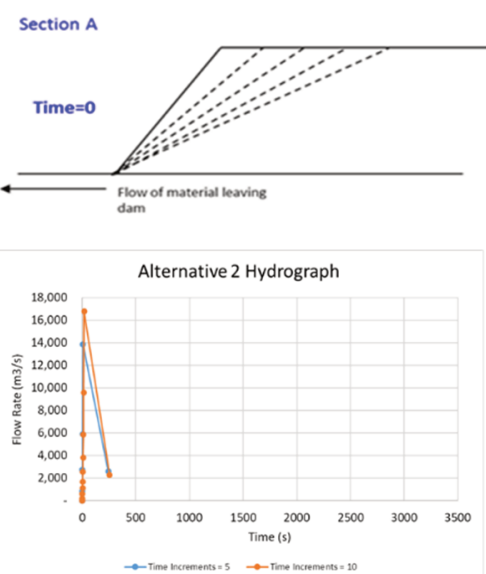

Alternative 3
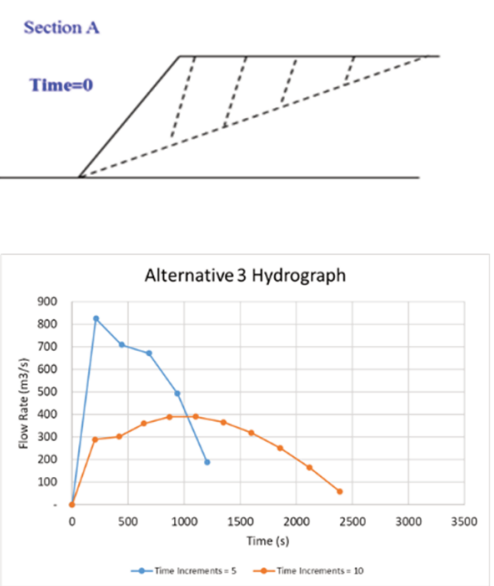

Figure 19 Alternative truncated cone outflow hydrographs 
When compared against past failures, it is evident that the cone provides a conservative estimate of the outflow volume as indicative from the residual craters in Figure 20.
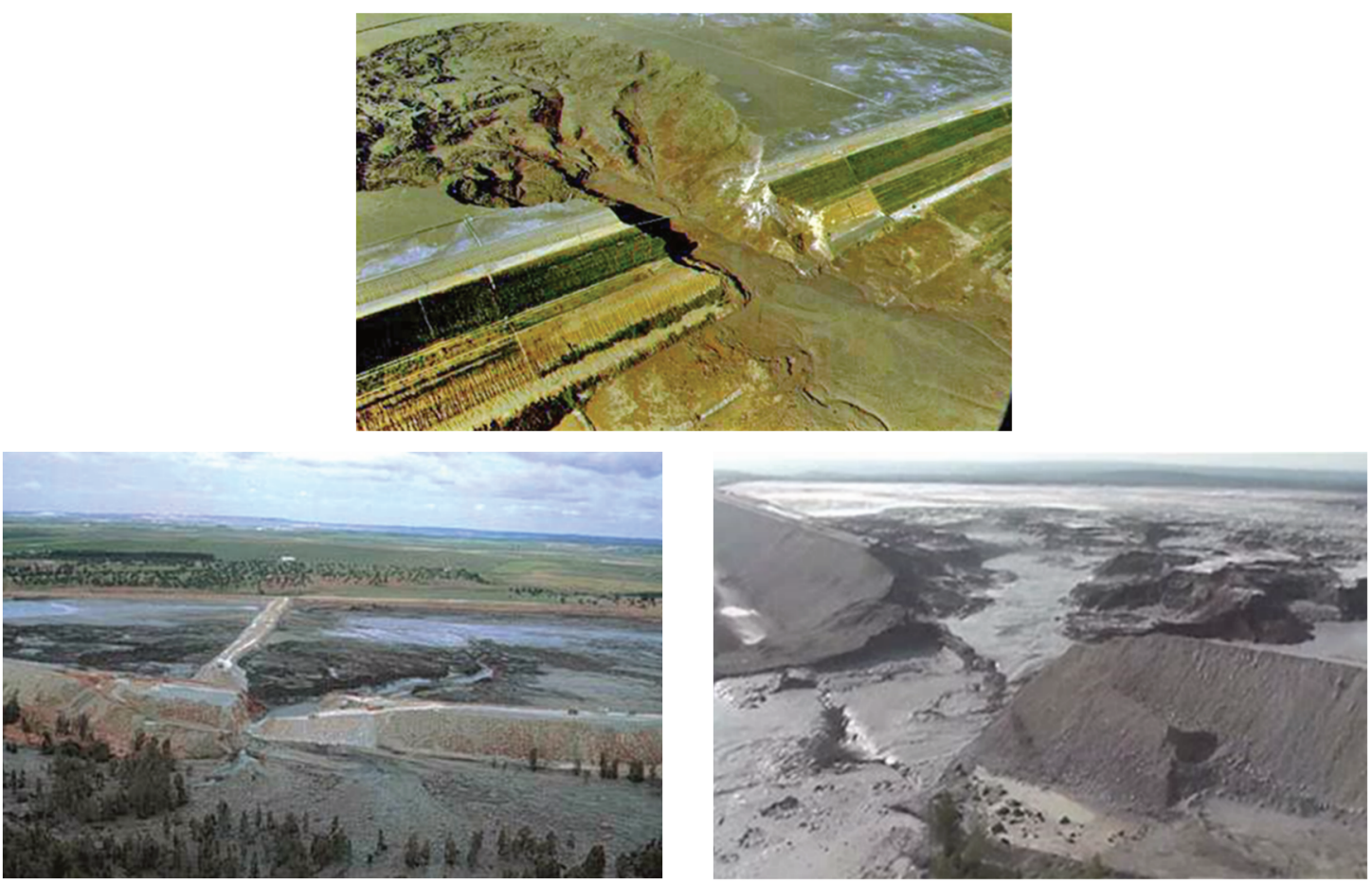

Figure 20 Representativeness of truncated cone approach

Deviations from the cone assumption in Figure 20 are caused by variability in the shear strength of the tailings which, in turn, is a result of deposition behaviour, pond management, and the extent to which drying and desiccation consolidation takes place in the tailings with successive depositions.

\subsection{Rheology of the liquefied residue}

Evaluation of the rheology of the liquefied tailings has been conducted using a 'box rheometer' apparatus, as indicated in Figure 21.
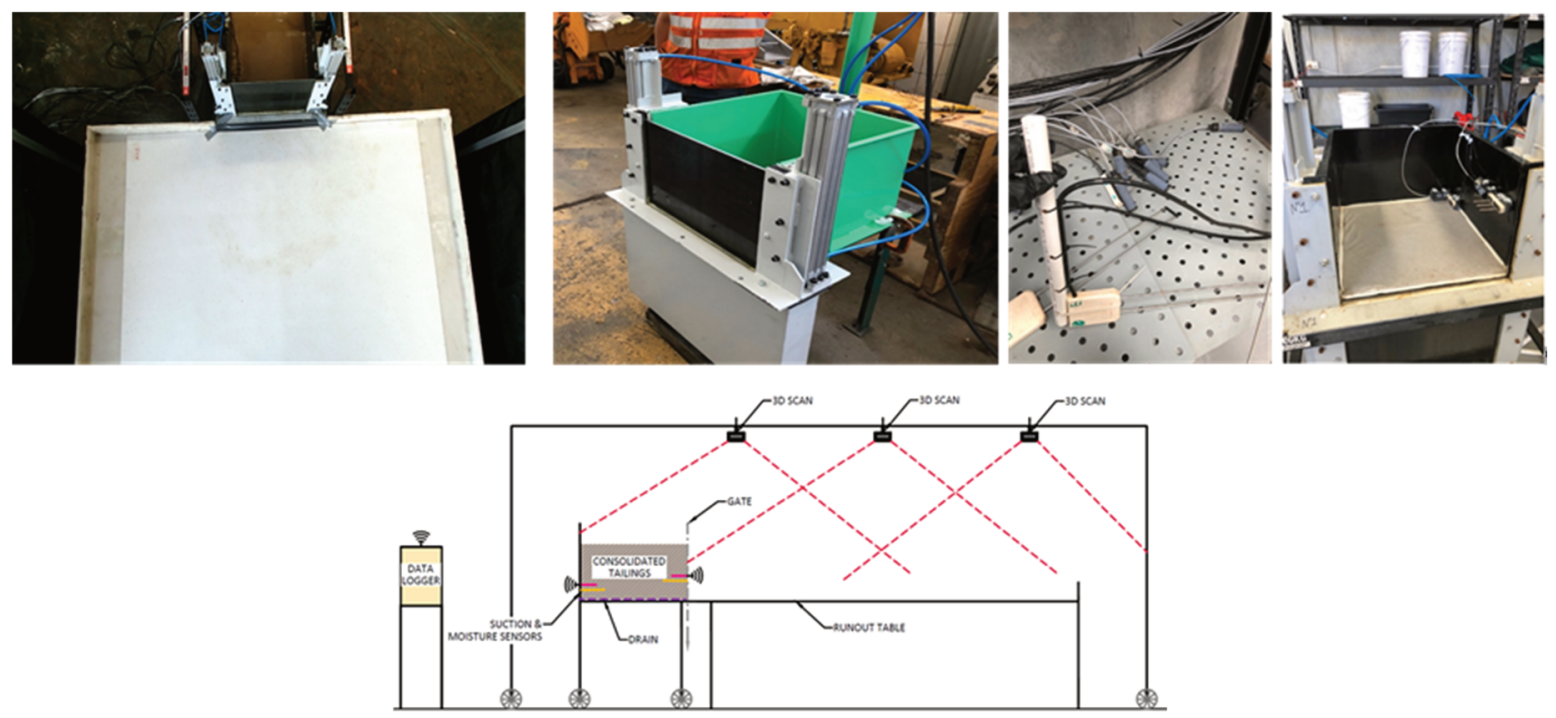

Figure 21 Apparatus for testing the rheology of liquefied residue 
The box rheometer comprises a $500 \mathrm{~mm} \times 500 \mathrm{~mm} \times 350 \mathrm{~mm}$ high steel box equipped with a sliding gate on one side. The box rheometer is loaded with residue with the gate raised. When the gate is opened, the reside flows out onto a $2 \mathrm{~m} \times 2 \mathrm{~m}$ table. Above the table are 3D cameras which capture the flow at 32 frames per second and provide data from which to analyse flow area, flow height, flow volume and therefore, outflow rate with time. Tests are conducted in parallel with rotary viscometer testing on samples recovered from the box immediately before and immediately after flow. Two sets of tests have been conducted:

- Tests with freshly mixed slurry for correlation with the rotary viscometer test results.

- Tests with aged and consolidated residue that is dried but still able to flow. During these tests, the boxes are instrumented with suction and moisture sensors which upload data to a datalogger.

Figure 22 shows a number of outflow results at a range of solids concentrations and ageing periods.
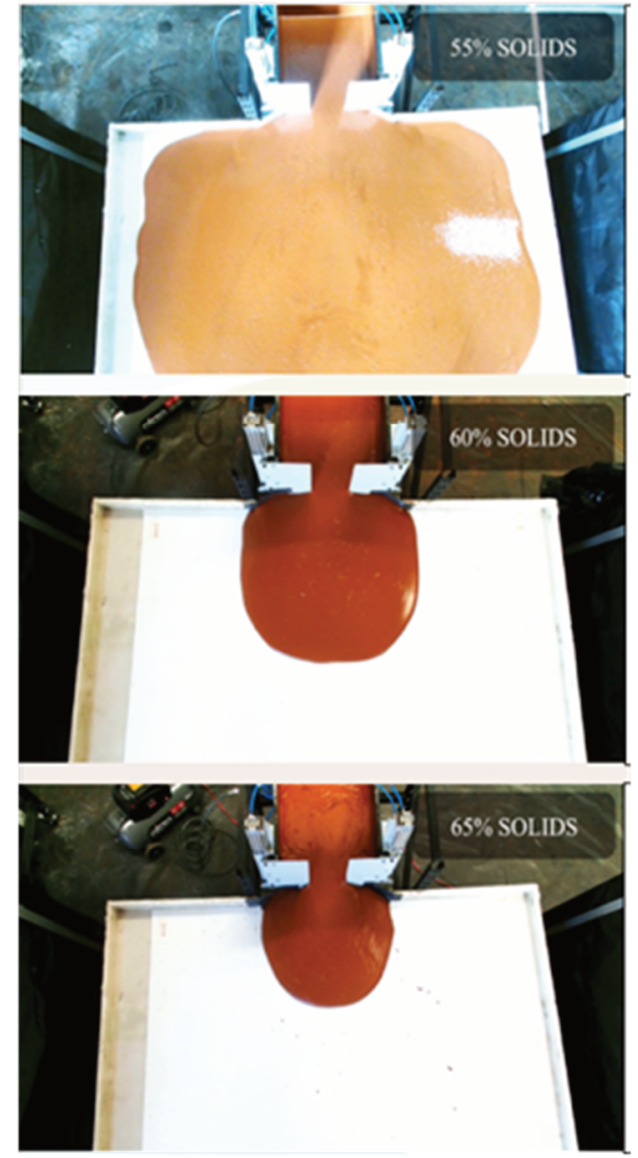

Freshly deposited slurry
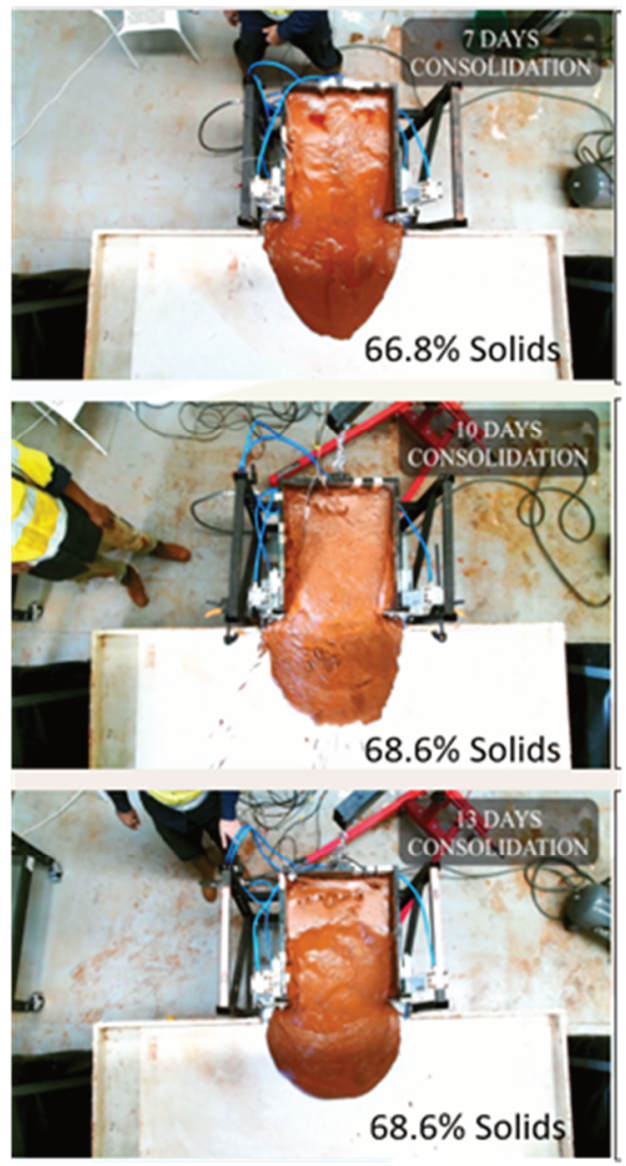

Sedimented and consolidated

\section{Figure 22 Typical outflow results with fresh slurry on the left and consolidated residue on the right}

Rheological parameters are calculated from the outflow results using McPhail's stream power entropy approach, as well as computational fluid dynamics (CFD) modelling using Flow3D as described by Ugaz \& McPhail (2021).

Figure 23 shows flow diagrams derived from the box rheometer and rotary viscometer tests. Rotary viscometer tests have been conducted on the unsheared residue sampled from the box immediately before opening. Also indicated are the rotary viscometer tests on fully sheared residue sampled from the box. It is evident that the rheology of consolidated residue is some four to five times greater than the rheology of fully sheared residue. 


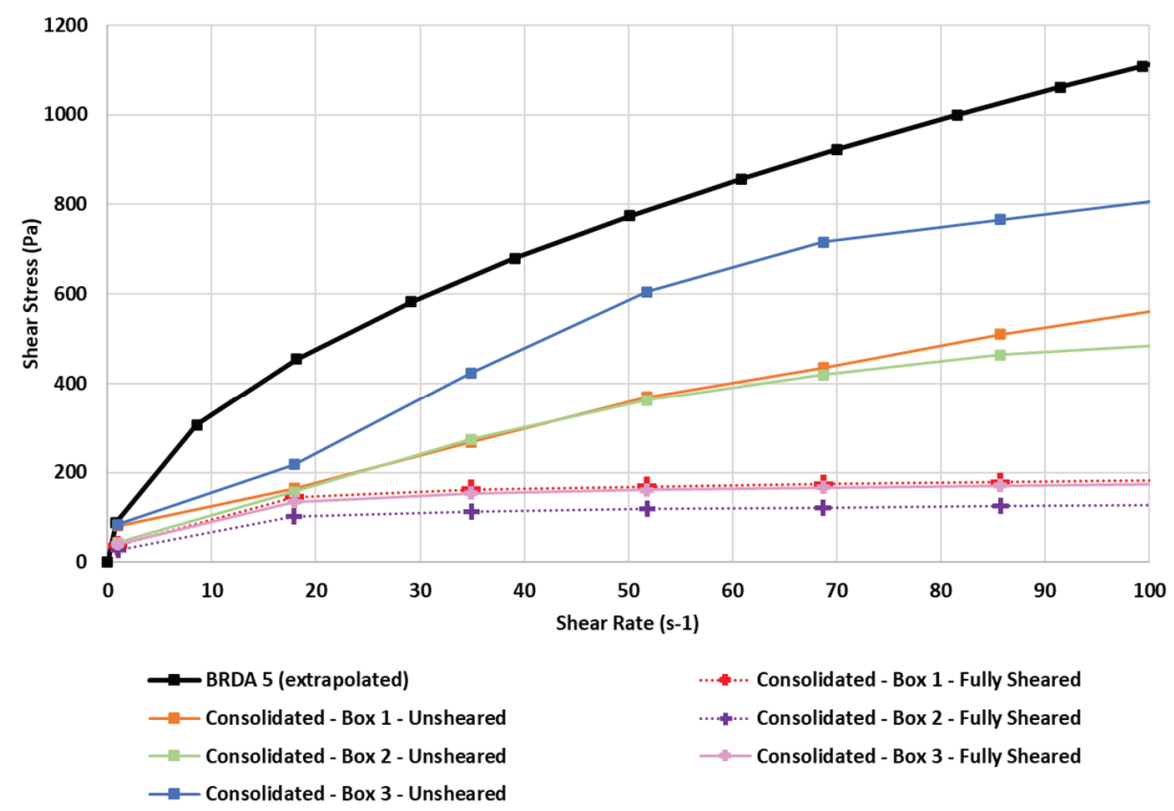

Figure 23 Flow curves based on power per unity mass

Monitoring and testing of the residue before flow enables the determination of the void ratio of the residue. Using the stress conditions in the box, in conjunction with the critical state line, enables estimation of the state parameter before flow. This information is useful because it provides a means for scaling from the box rheology to the rheology in the field based on critical state data within BRDA5.

Figure 24 shows the state parameter plotted onto the critical state line plots.

CSL-Reconstitued Triaxial Test- Worsley

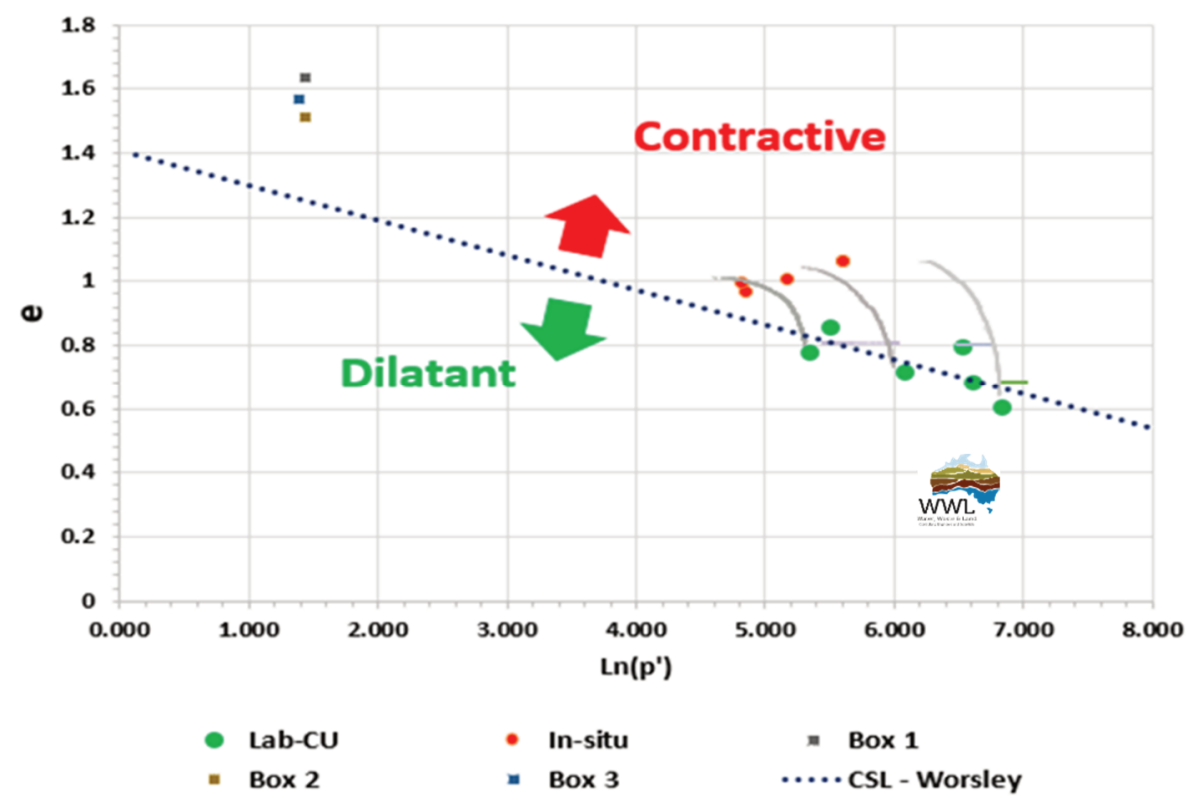

Figure 24 Critical state line from triaxial laboratory testing

Figure 25 shows the screening level estimates of the state parameter from CPTu testing and Figure 26 shows the flow curve derived for the in situ residue based on scaling of the state parameters from the box to the field condition. 
$\Psi$ (Plewes)

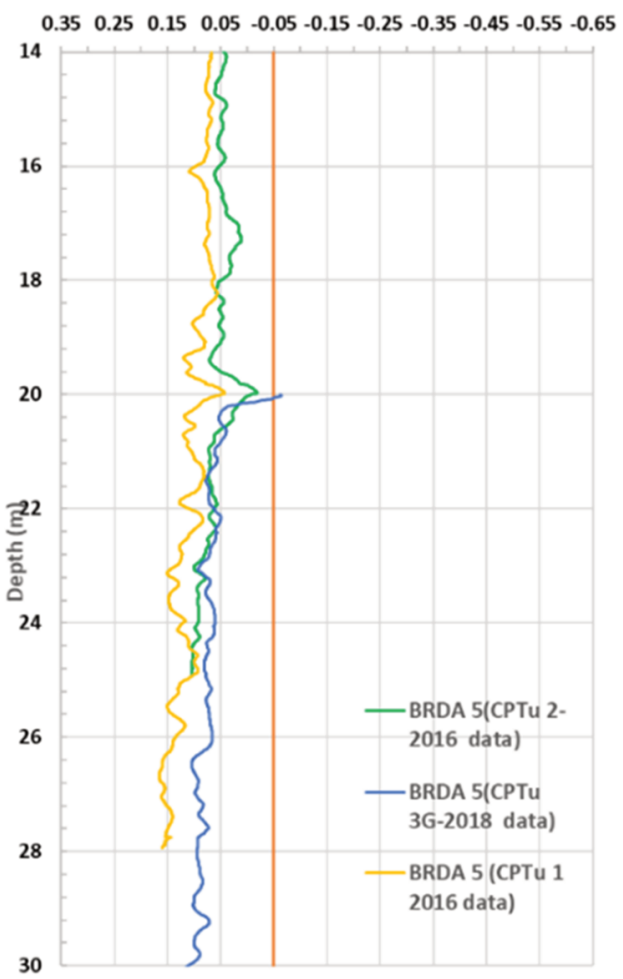

Figure 25 Screening level state parameters from CPTu testing

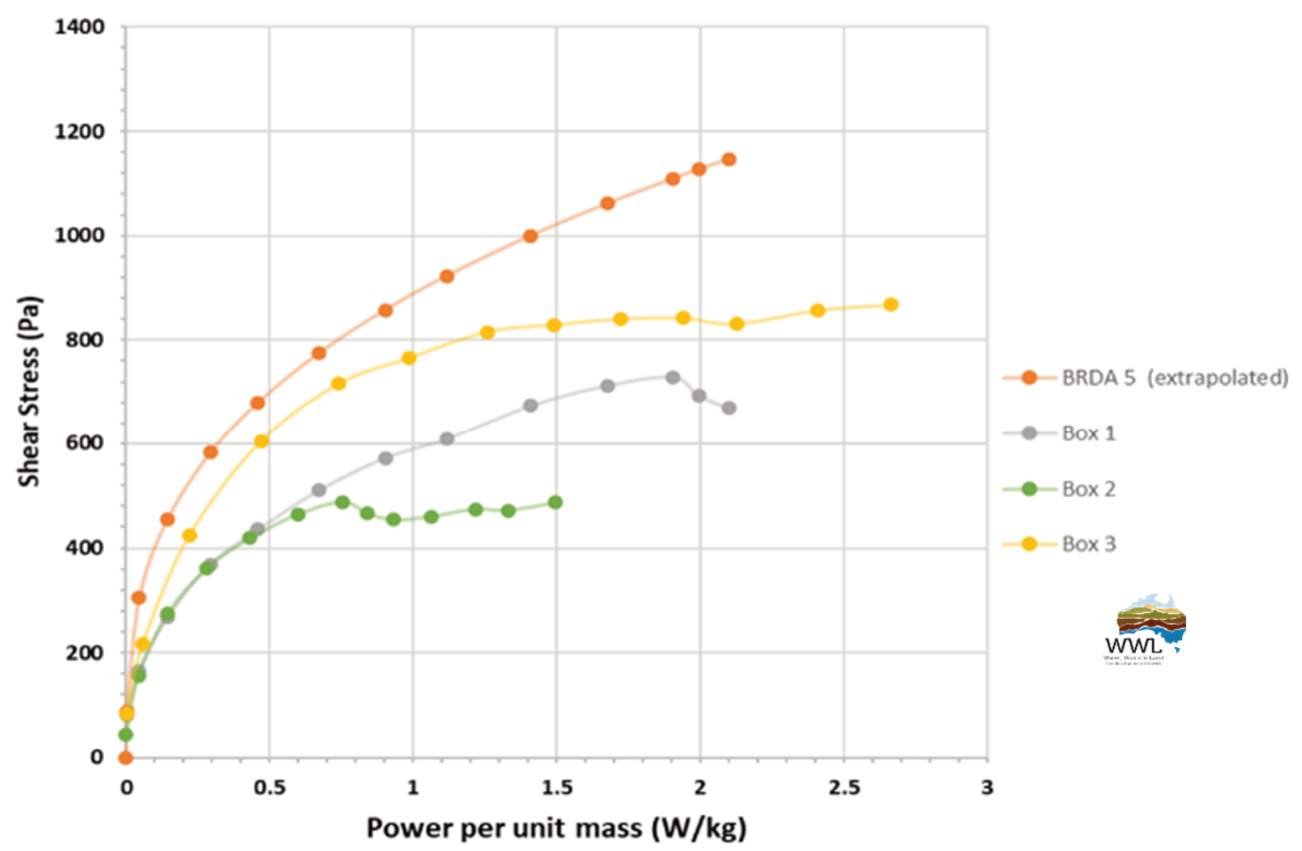

Figure 26 Flow curve incorporating field state parameter levels in BRDA5

\subsection{Liquefaction flow modelling}

Liquefaction flow modelling from BRDA5 has been conducted using a model based on McPhail's stream power entropy approach (McPhail 1995, 2014, 2015) combined with the approach of Blight et al. (1981), as well as with CFD. 
The modelling approach of Blight et al. (1981) has been supplemented by the stream power entropy equations to allow a closed form solution at each section in pseudo 2D flow. The model incorporates:

- Standard fluid mechanics equations solved over sections along the flow path as described by Blight et al. (1981).

- An assumption that the cross-sectional profile of the flowing mass is an ellipse to take account of the drag effects at the edges of the mass.

- Conical failure modes for hydrograph estimation.

- Rheology as documented above.

- Manning roughness taking into consideration the laminar flow characteristics of the flowing mass and the fact that the mass is non-Newtonian.

Creep, which sets in when the Reynolds number approaches unity, is brought in in post processing of the model results.

The closed form solution of the model makes it practical to carry out probabilistic modelling to develop confidence limits in the inundation characteristics. The key parameters that are varied using uniform distributions in the analyses are:

- USRpeak based on minima and maxima from the geotechnical assessments.

- USRpost liquefaction based on minima and maxima from the geotechnical assessments.

- Manning roughness based on minima and maxima from literature.

- Rheology based on a practical range from the rheological testing scaled according to state parameter.

- Number of slices in the conical crater.

Two liquefaction flow cases have been modelled:

- Flow from the topmost layer of freshly poured residue. For this situation, the residue is still a fluid and the fresh slurry rheology is applicable. The volume of residue released is applied in a uniform distribution with values ranging from 150,000 to $300,000 \mathrm{~m}^{3}$.

- Flow from release of the residue down to ground level. The USR parameters generated a volume range of 400,000 to $900,000 \mathrm{~m}^{3}$.

Figure 27 shows the inundation area and confidence limits for flow from the uppermost layer of residue. Figure 28 shows the resulting flow profile down the centreline of the flow.

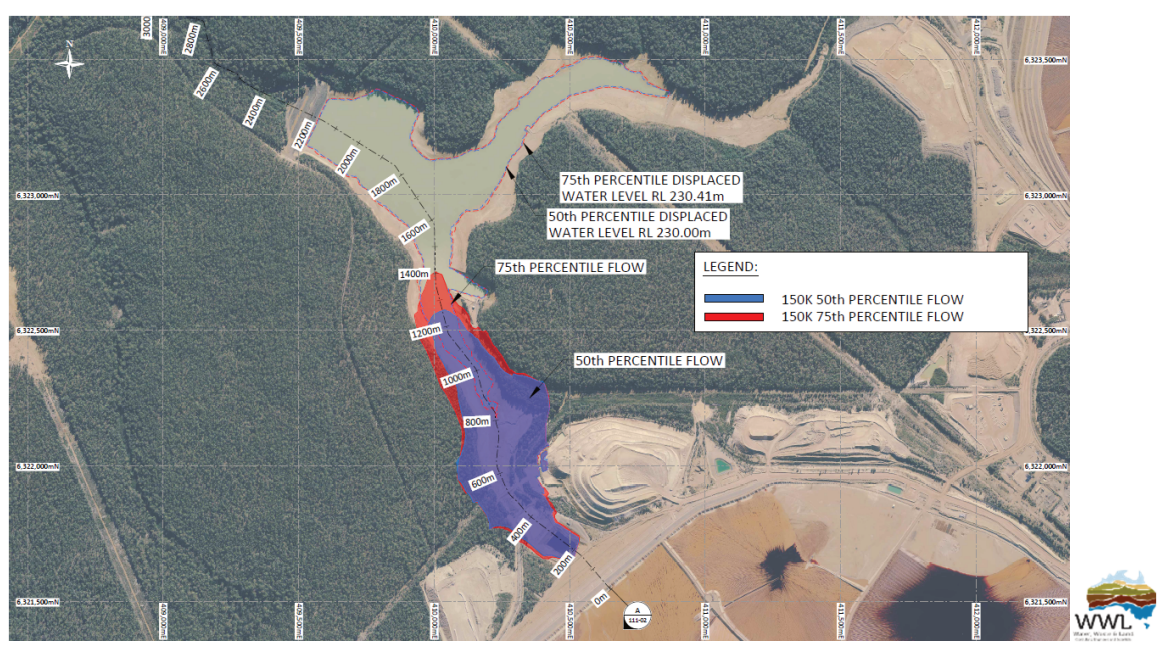

Figure 27 Inundation area confidence limits for failure of the uppermost layer of residue 


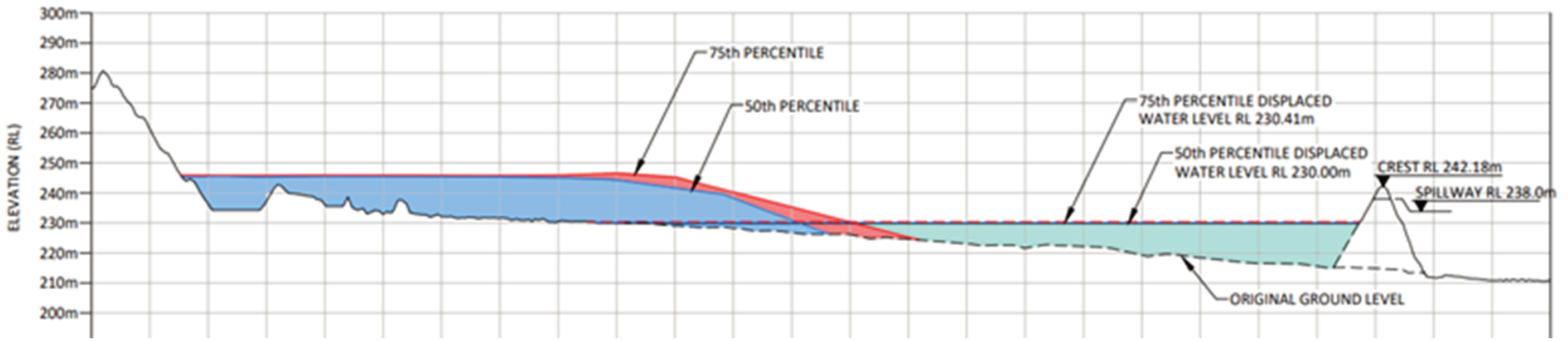

Figure 28 Section through-flow mass with confidence limits for failure of the uppermost layer of residue

CFD modelling of flow from the uppermost layer has been carried out using the fresh slurry rheology. Output part way through the model is shown in Figure 29. The final outflow is similar to that predicted by the stream power entropy modelling but the CFD modelling is too computationally intensive to carry out probabilistic modelling.

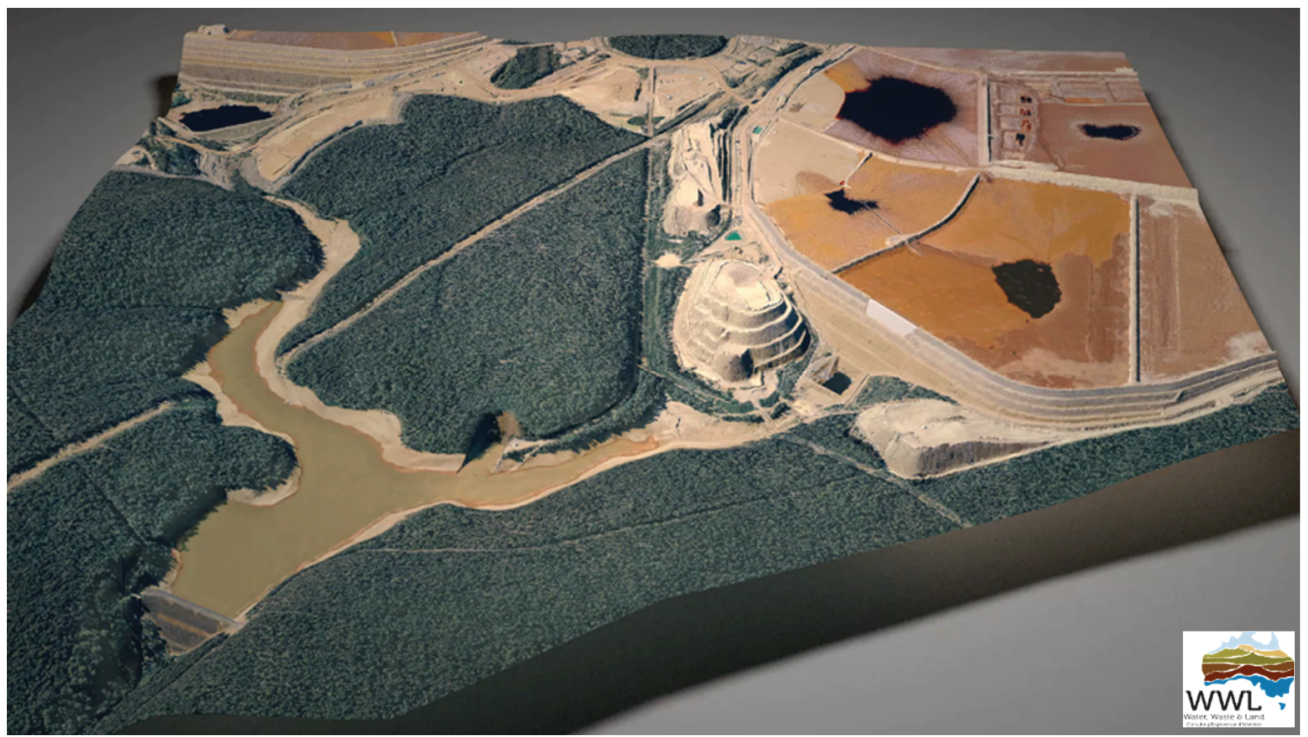

(a)

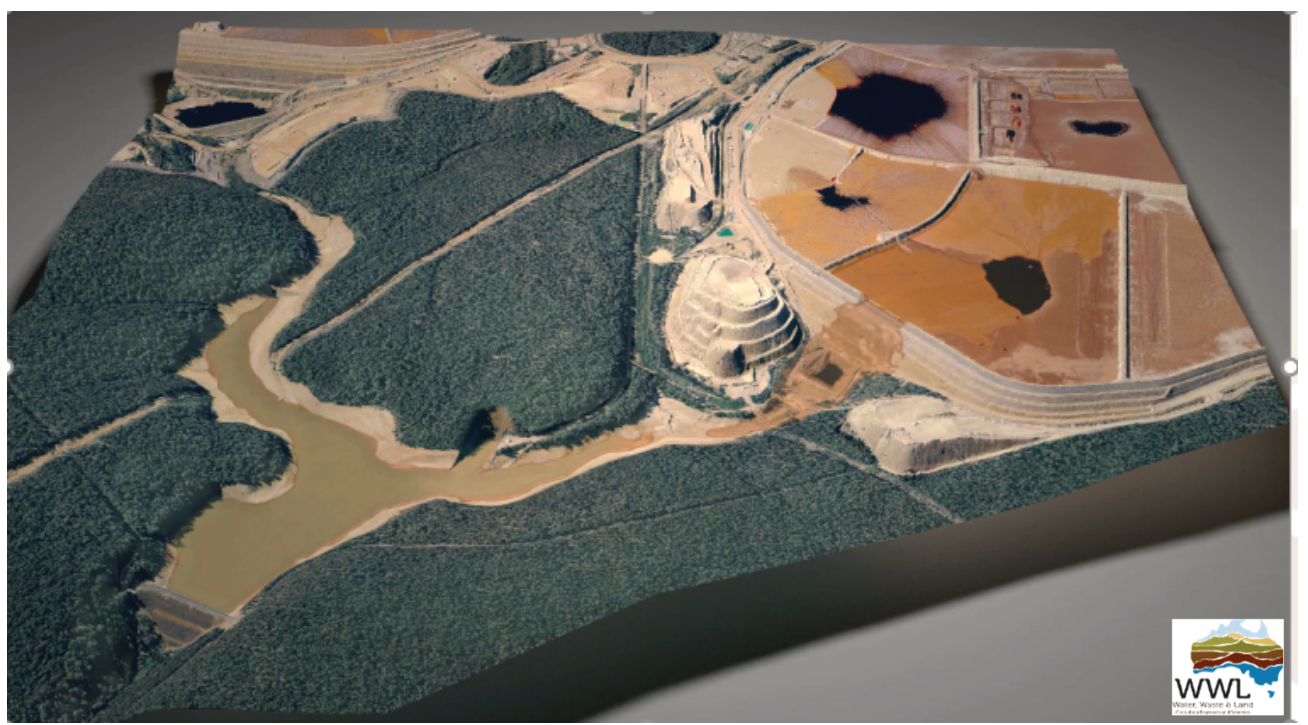

(b) 


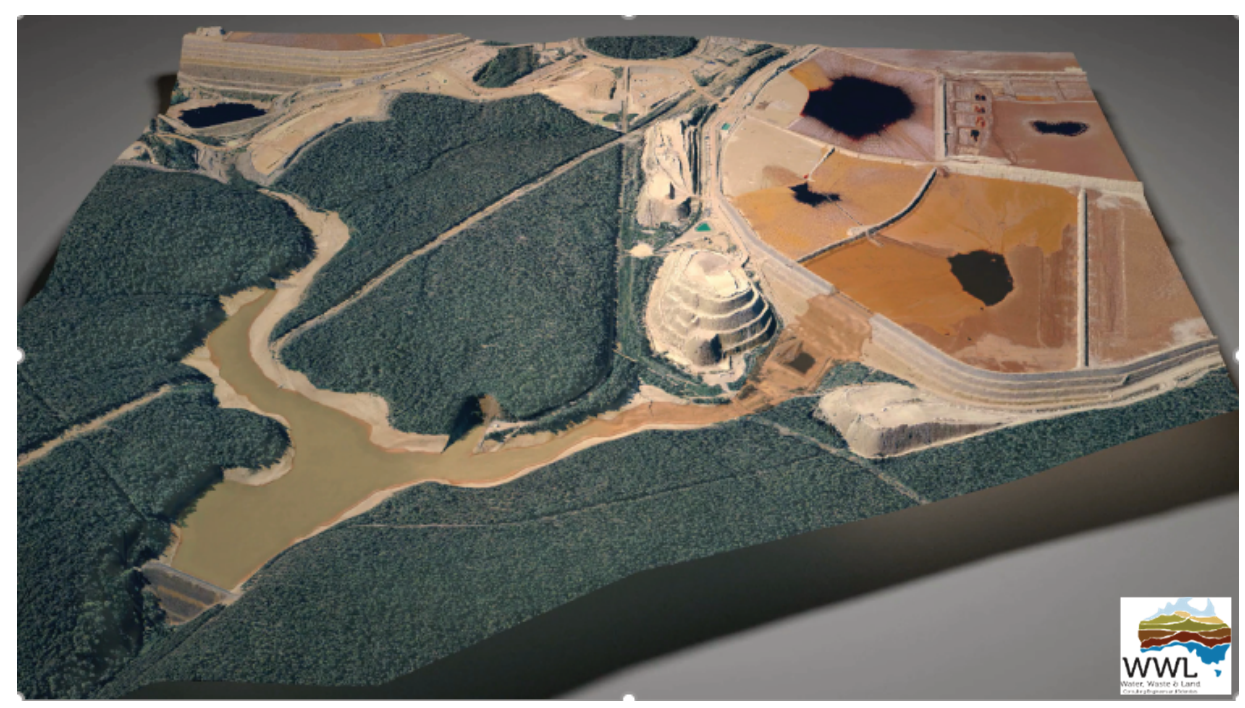

(c)

Figure 29 Output from CFD modelling of failure of the uppermost layer of residue: (a) Before failure; (b) During flow; (c) After flow

Figure 30 shows the inundation area produced in the modelling of the full depth dam break and Figure 31 shows the flow profile along the centreline of the flow.

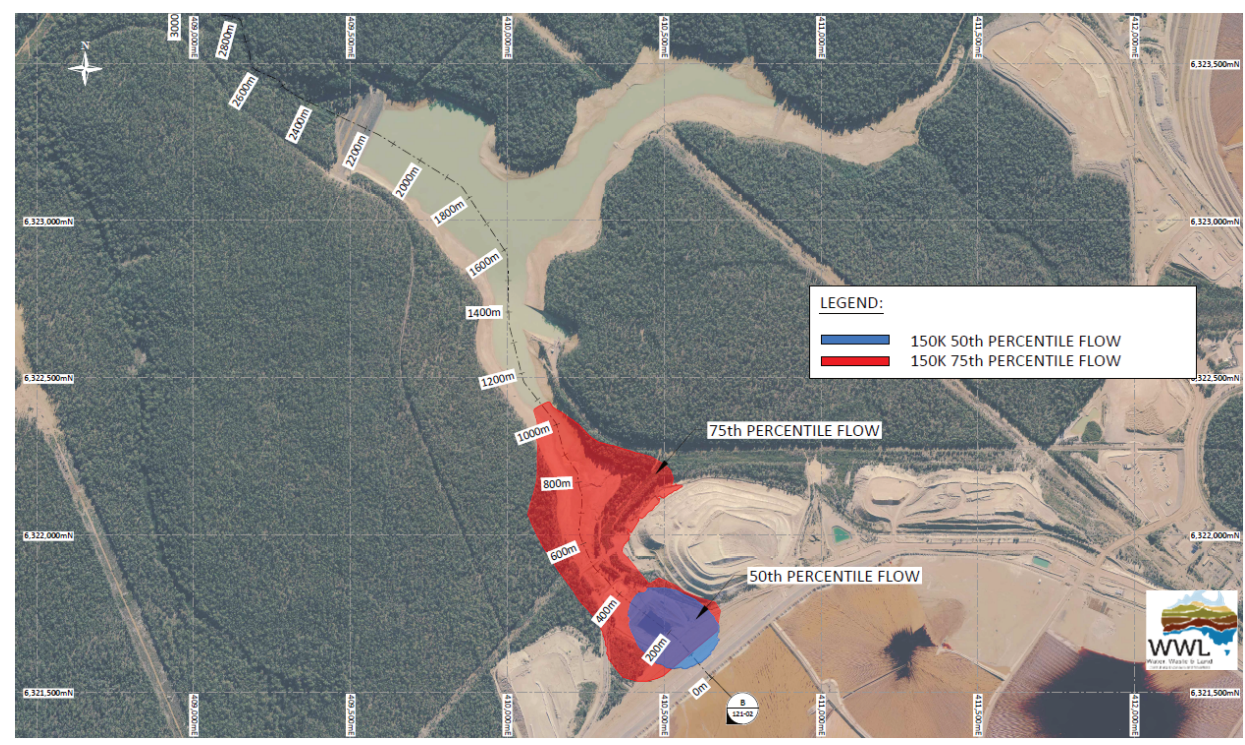

Figure 30 Inundation area with confidence limits for flow from the full depth of residue

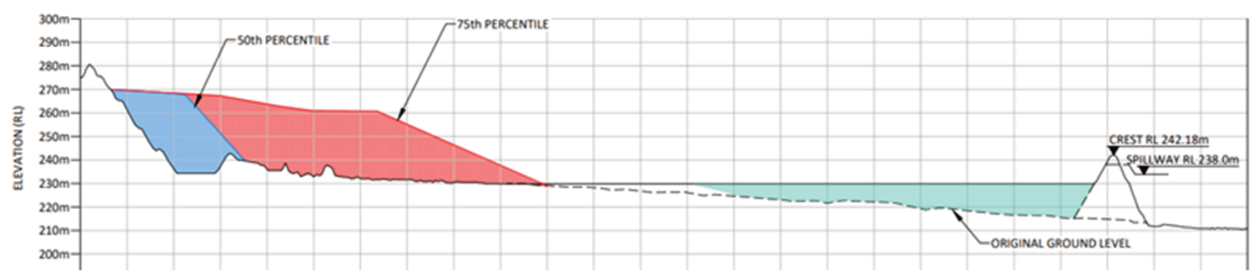

Figure 31 Section through flow mass with confidence limits for flow from the full depth of residue

It is evident from Figures 27 to 31 that the liquefied residue does not flow beyond the freshwater lake. This is a significantly different result from previous dam break modelling in which the flow of the liquefied residue is based on the rheology of dilute fresh slurry. 


\subsection{Assessment of tsunami}

As the liquefied residue enters the freshwater lake, there is a risk that this generates a tsunami wave that could overtop the freshwater lake embankment. This has been assessed using the approach of Heller et al. (2009). Figure 32 shows the output from the analysis which is based on the freshwater lake being at full supply level when the dam break occurs. The wave height is less than $1.7 \mathrm{~m}$ which is less than the embankment freeboard at full supply level.
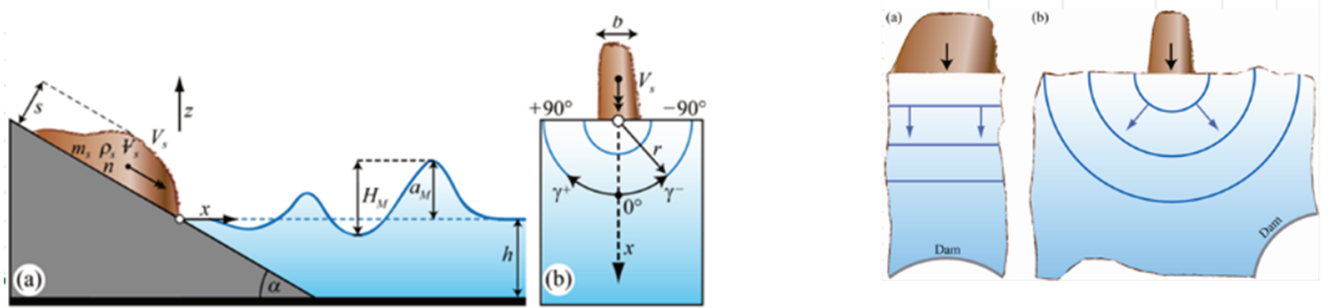

CASE 1 WAVE CAL.

\begin{tabular}{|l|r|}
\hline Streamwise distance of the maximum wave amplitude from the impact location $x_{M}[\mathrm{~m}]$ & 85.6 \\
Wave height $H\left(H_{M}\right)[\mathrm{m}]$ & 1.5 \\
Wave amplitude $a\left(a_{M}\right)[\mathrm{m}]$ & 1.2 \\
Wave period $T\left(T_{M}\right)[\mathrm{s}]$ & 12.6 \\
Wave celerity $c[\mathrm{~m} / \mathrm{s}]$ & 18.0 \\
Wave length $L\left(L_{M}\right)[\mathrm{m}]$ & 226.7 \\
\hline
\end{tabular}

CASE 2 WAVE CAL.

\begin{tabular}{|l|r|}
\hline Streamwise distance of the maximum wave amplitude from the impact location $x_{M}[\mathrm{~m}]$ & 93.3 \\
Wave height $H\left(H_{M}\right)[\mathrm{m}]$ & 1.7 \\
Wave amplitude $a\left(a_{M}\right)[\mathrm{m}]$ & 1.4 \\
Wave period $T\left(T_{M}\right)[\mathrm{s}]$ & 13.0 \\
Wave celerity $c[\mathrm{~m} / \mathrm{s}]$ & 18.1 \\
\hline Wave length $L\left(L_{M}\right)[\mathrm{m}]$ & 235.3 \\
\cline { 2 - 3 }
\end{tabular}

Figure 32 Results of tsunami analysis

\section{Conclusion}

This paper has described in detail the various approaches and analyses carried out for the dam break assessment of BRDA5 at WARL. The results are based on site specific data that has been benchmarked with alternative test and analysis methods. There are two zones of concern within BRDA5. One is the topmost layer of residue immediately following a pour and before amphirolling benefits have taken effect. For these materials, if the confining embankment were to be eroded away by rainfall or leaks from a pipe burst, there is potential for liquefied residue to flow down to the freshwater lake.

The second zone is below the level of the starter embankment. If the support of the starter embankment were to be removed as a result of slope failure or severe erosion, there is potential for liquefied residue to flow to the freshwater lake.

A semi-quantitative risk assessment based on a fault-event analysis approach has been completed. This incorporates the results of an FMEA carried out to assess the effectiveness of monitoring and control measures. The fault-event analysis has enabled the estimation of the probability of loss of life due to a dam break on BRDA5.

A dam break assessment that considers the flow of liquefied residue has been carried out with the incorporation of non-Newtonian fluid properties representative of liquefied consolidated residue. The rheological properties of the liquefied consolidated residue have been estimated from pilot-scale dam break tests using a 'box rheometer'. Comparison of this rheology with the rheology of fully sheared slurry shows the consolidation process increases the rheology by a factor of 4 to 5 . The rheology of liquefied consolidated residue in the box rheometers has been scaled through the state parameter to estimate the rheology of the liquefied residue that would be released from BRDA5. 
Probabilistic modelling of the release of liquefied residue from BRDA5 has been carried out by estimating the outflow hydrograph using a conical residual cavity whose dimensions are determined by the peak and residual undrained shear strength of the residue. The modelled inundation areas have been developed with confidence limits. The results of the probabilistic modelling have been compared with deterministic modelling using CFD and are shown to have similar inundation geometries.

The inundation areas for the liquefaction flow of residue are significantly less extensive than previous assessments and have resulted in a reduction in insurance premiums for WARL. The fault-event based risk assessment has also highlighted areas in which operational monitoring can be improved to lower the risks still further.

\section{Acknowledgement}

The authors express their appreciation to WARL and South32 for permission to present this paper.

\section{References}

Blight, GE, Robinson, ME \& Diering, JAC 1981, 'The flow of slurry from a breached tailings dam', Journal of the South African Institute of Mining and Metallurgy.

Heller, V, Hager, WH \& Minor, HE 2009, 'Landslide generated impulse waves in reservoirs: basics and computation', Mitteilungen 211, Versuchsanstalt fur Wasserbau, Hydrogie und Glaziologie (VAW), Zurich.

McPhail, G 1995, Prediction of the Beaching Characteristics of Hydraulically Placed Tailings, PhD thesis, University of the Witwatersrand, Johannesburg.

McPhail, GI 2014, 'Using small scale flumes to determine rheology at low shear rates', in S Barrera (ed.), Proceedings of the 2nd International Seminar on Tailings Management, Gecamin, Santiago.

McPhail, G 2015, 'Probabilistic dam break assessment and flow slide analysis for tailings storage facilities', Proceedings of the 3rd International Seminar on Tailings Management, Gecamin, Santiago.

Robertson, PK 2016, 'Cone penetration test (CPT)-based soil behaviour type (SBT) classification system - an update', Canadian Geotechnical Journal, vol. 53, no. 12, https://doi.org/10.1139/cgj-2016-0044

Sadrekarimi, A 2014, 'Effect of the mode of shear on static liquefaction analysis', Journal of Geotechnical and Geoenvironmental Engineering, vol. 140, issue 12.

Schneider, JA, Hotstream, JN, Mayne, PW \& Randolf, MF 2012, 'Comparing CPTUQ-FandQ-Du2/sv09soil classification charts', Geotechnique Letters 2, vol. 2, no. 4, pp. 209-215.

Ugaz, R, \& McPhail, G 2021, 'Determination of the rheology of liquefied bauxite residue using a pilot scale dam break test', Proceedings of the 7th International Conference on Tailings Management, Gecamin, Santiago. 